Migration: Economically Motivated or a Matter of Networks? A Case Study of Migration from Eastern Europe to Germany

\author{
Ella Maria van der Haar \\ Amsterdam, The Netherlands
}

B.A., University of Amsterdam, 2013

A Thesis presented to the Graduate Faculty of the University of Virginia in Candidacy for the Degree of Master of Arts

Department of Politics

University of Virginia

December 2014 


\title{
Migration: Economically Motivated or a Matter of Networks? A Case Study of Migration from Eastern Europe to Germany
}

\author{
Ella Maria van der Haar
}

December 2014

\begin{abstract}
What determines migration? More specifically, what factors influence the decision of migrants to migrate? This paper explores the relative importance of economic migration arguments versus migrant network parameters on a regional level in explaining and predicting migration flows. It employs new data on migration from Eastern European New Member States to Germany and its respective Bundesländer between 2000 and 2012. This paper aims to determine whether traditional neoclassical economic theory can be extended with elements of migrant network theory to create a more complete theory that is more effective in explaining migration flows in the case of predicting migration to different regions within a country. Using fixed effects regression models this paper finds that both economic as well as network variables have a strong and positive impact on migration flows from the Eastern European New Member States .
\end{abstract}




\section{Acknowledgements}

I would like to thank my supervisor Professor Sonal Pandya for her guidance and feedback throughout this project. Our inspiring meetings and discussions have greatly aided me in writing this thesis. At times I was struggling with focussing my research question and frustrated with the research effort, but Professor Pandya helped me realize what an interesting learning process such a project is, which greatly motivated me to continue writing. Also many thanks to Professor David Leblang for his valuable feedback and for inspiring me to focus my research on migration to Germany. Furthermore, I would like to express my gratitude to the Department of Politics at the University of Virginia for allowing me to continue working on my thesis from the Netherlands, and trusting me to deliver this research effort from a distance. 


\section{Contents}

\begin{tabular}{lll}
\hline 1 & Introduction & 1
\end{tabular}

2 Migration Theory 5

2.1 European Migration . . . . . . . . . . . . . . . . . . . 12

2.2 East-West Migration . . . . . . . . . . . . . . . . . . . . . . . . 13

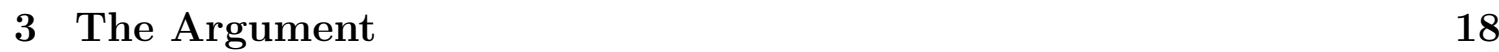

\begin{tabular}{|lll}
4 & Testable Hypotheses & 21
\end{tabular}

4.1 Hypotheses . . . . . . . . . . . . . . . . . . . . 21

4.2 Selection Effects and Ideal Experiment . . . . . . . . . . . . . . . . . 24

5 Sample and Data 30

5.1 Sample . . . . . . . . . . . . . . . . . . . . . . . . 30

5.2 Migration Data . . . . . . . . . . . . . . . . . . . . . . . . . 31

5.3 Economic parameters . . . . . . . . . . . . . . . . . . . . . . . . . . . . . . . . . . . . . .

5.4 Migrant Networks . . . . . . . . . . . . . . . . . . . . . . . . . . . . . 34

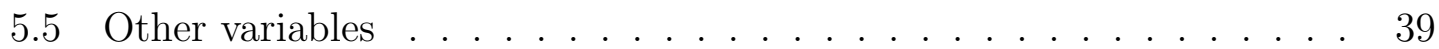

$\begin{array}{lll}6 & \text { Empirical Analysis } & 44\end{array}$

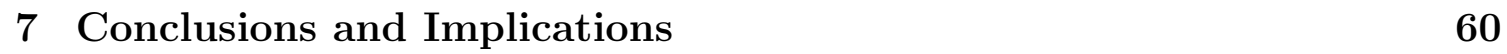




\section{Introduction}

International migration has become a reality for the majority of industrialized countries, yet the theoretical base for understanding migration movements is not sufficiently developed and there is no single, coherent theory of international migration available $!^{1}$ With the recent developments in the European Union concerning the accession of new member states, there has been an extensive debate about the consequences of allowing new countries to access the Western European labor market. It was feared that this would flood the Western labor markets as a result of the large differences in wages and unemployment rates between Eastern and Western Europe.

However, when looking at the accessions of Greece, Portugal and Spain between 1981 and 1986 and the recent accessions of a number of Eastern European countries in 2004 and 2007, it can be stated that the predictions of massive migration waves after the opening of the borders to labor were exaggerated, and migration levels turned out to be much lower than was predicted by wage and employment differentials..$^{2}$ Interestingly, the rates of outmigration from the EU8 countries ${ }^{3}$ and the EU2 countries $4^{4}$ vary more than would be predicted under the most popular and widely tested Neoclassical Economic Migration Theory. This theory predicts that we should observe an increase in migration flows as wage and unemployment differentials in-

\footnotetext{
${ }^{1}$ Massey, D.S. et al. "Theories of International Migration: A Review and Appraisal"

${ }^{2}$ World Bank "Chapters on Migration", pp. 78

${ }^{3}$ EU8: Czech Republic, Estonia, Hungary, Latvia, Lithuania, Poland, Slovakia and Slovenia, excluding Malta and Cyprus (EU enlargement in 2004)

${ }^{4}$ EU2: Bulgaria and Romania (EU enlargement in 2007)
} 
crease. However, it should be noted that neoclassical economic theory does not take into account that migrants consider a much broader range of variables determining their decision to migrate, such as several psychological and physical costs. It also does not capture the benefits of migrant networks for potential migrants. Recently, Migrant Network theory has been trying to fill this gap, by looking at the effects of early migrants settling in a country on later migration flows to the same region, including the social and psychological costs of migration.

This paper will focus on migration movements from the Eastern European New Member States $\mathrm{s}^{5}$ to the German Bundesländer $\bigsqcup^{6}$ between 2000 and 2012, including the 2004 and 2007 European enlargements. Germany was selected as destination country for this study because it is one of the most popular destination countries for migrants in the European Union. What makes Germany unique is its convenient and central geographic location, which makes it easily accessible for migrants from the surrounding Eastern European countries. Also, historically many people in Eastern Europe have been frequently exposed to German language and culture. Not only is Germany considered a relatively familiar destination, it is also one of the richest and most successful economic in the Eurozone, thus making it a very relevant and important country to study. Another reason to study Germany is that the German Statistical Agency and other German federal institutions have been collecting a tremendous amount of very accurate and detailed migration data, both at the country as well as the state level, which is easily accessible and can be used to study migration flows

\footnotetext{
5 "New Member States": all the Eastern European countries that joined the European Union in 2004 and 2007.

6 "Bundesländer": Germany's sixteen Federated States.
} 
to the different regions within the country.

The case of migration to Germany poses several theoretical and empirical puzzles. First, migration theory predicts that migration should increase strongly if wage differentials are large. Does the moderate migration from Eastern European undermine these theories? Second, why do migrants choose to locate in different Bundesländer, despite economic conditions in those destinations? And lastly, when looking at the migration flows to the different Bundesländer, do these economic and network parameters also play a predictive role for migration flows on a regional level?

This paper investigates to what extent current international migration theory accurately predicts migration flows from Eastern Europe to the the German Bundesländer between 2000 and 2012, and whether there is a role for migrant networks in explaining these movements. If the findings of this paper confirm that wage and unemployment differentials play a role on a regional scale, this can provide useful insights both for improving existing theories about migration as well as providing new insights for policy makers. It is important for researchers and policymakers to understand why migration flows were not as large as was feared, and what methods were successful in predicting these flows. Due to availability of new data, questions about migration to different regions within Germany can be answered. On the other hand, if the results remain inconclusive regarding the impact of wage and unemployment differentials, this indicates that migrant networks and other facilities for migrants in the receiving countries are potentially relevant determinants of migration movements. By attempting to measure the size of migrant networks and correlating this with migration movements to the respective Bundesländer, we will also gain more insight 
as to which circumstances lead to fluctuations in migration. The proposed variables and subsequent analysis are limited to the German case. However, the findings of this paper allow us to draw inferences about migration flows within a country, which can potentially be extrapolated to other cases in future research.

In this paper I will argue that neoclassical economic theory and migrant network theory should not be regarded as two excluding theories, but rather as two different positions on a sliding scale. The theories based on economic parameters place more emphasis on the economic incentives for migration, whereas the migrant network approach is based on the idea that an established network of migrants of the same nationality can lower the costs of migration, thus providing an incentive to migrate. Therefore, both are inherently theories of a calculation of expected costs and benefits. However, it should be noted that whereas neoclassical economic theory is focused on economic gains of migration, network theory also includes the importance of family and other people of the same nationality establishing networks in order to lower emotional and information costs. Thus, the basic idea of cost calculation and assessment of gains is similar, but the costs consist of different elements.

The first part of this paper will synthesize the existing migration literature and the research that has been done on migration in the European Union and to Germany in particular, and will identify the strengths and shortcomings. The second part of this paper will be devoted to clearly formulating the theoretical puzzle and generating a number of testable hypotheses. In the last part of this paper these hypotheses will be tested with new data. This paper will be concluded with a discussion of the implications of the findings and suggestions for future research. 


\section{Migration Theory}

What causes people to migrate? That is, based on which factors do people decide whether to move to a different country or remain in their home country, and how have these questions been answered by theorists and researchers? This section will break down the existing literature on migration theory, and critically evaluate the shortcomings of those theories in explaining migration flows in the European Union and to Germany in particular. It will also suggest ways in which these theories can be applied to answering the main question of this paper, namely, what best explains the patterns in outmigration from the Eastern European New Member States to the German Bundesländer.

Both Massey ${ }^{7}$ and Kurekove 8 provide an extensive review of theories of international migration. They distinguish between two different views on migration, which is viewed either as the result of structural factors or the result of individual decision making. The most commonly used and extensively tested version of migration theory is Neoclassical Economic Theory? which distinguishes between a macro and a micro perspective. The macro variant is based on the idea that migration is caused by "geographic differences in the supply and demand of labor" 10 Thus, migrants are considered to be more likely to move from low wage countries where there is a surplus of labor, to high wage countries where labor is scarce. The most important

\footnotetext{
${ }^{7}$ Massey, D.S. et al. (1993) "Theories of International Migration: A Review and Appraisal" ${ }^{8}$ Kurekova (2011) "Theories of Migration: Conceptual Review and Empirical Testing in the Context of the EU East-West Flows"

${ }^{9}$ Massey et al. (1993), pp. 433

${ }^{10}$ Massey et al. (1993), pp. 433
} 
assumptions of this theory are that international migration is caused by wage differentials and differences in unemployment rates, and that the elimination of these wage differences will bring an end to migration.

Thus, in the case of migration from Eastern Europe, we would expect based on this theory that an increase in the wage differences between the Eastern European New Member States and the respective German Bundesländer would lead to an increase in migration, until wage and unemployment differentials equalize. Migration from the East to the West will come to an end if the equilibrium is maintained. This however, leads to the main critique on macro level neoclassical migration theory, namely that it assumes linearity ${ }^{11}$ and therefore cannot explain why some people decide to migrate and others do not even if they face the same economic differentials. Furthermore, neoclassical economic theory does not take into account the role of politics and policies in migration decision making and is not able to account for the fact that markets are not perfect. In other words, it assumes the labor market to be perfectly elastic, thus enabling it to respond to changes in wages immediately. However, in reality this proves to be an oversimplification. Nonetheless, this theory has been used extensively due to its simplicity and empirical applicability. Therefore I choose not to disregard this theory at first glance, but to opt for improvements that can be made to yield more accurate predictions and explanations.

Both macro-level and micro-level neoclassical economic theory assume that decisions are made based on rational calculations of costs and benefits by potential migrants.12

\footnotetext{
${ }^{11}$ Neoclassical economic theory assumes that the size of migration flows will vary linearly with economic differentials.

${ }^{12}$ Kurekova (2011), pp. 4
} 
In the micro model, when individual rational actors decide to migrate when their expected returns are higher when migrating, they are also taking into account the costs that are associated with migration, such as the material costs of traveling, the probability of employment in the destination region, and their personal preference for risk 13 The micro variant of neoclassical economic migration theory thus adds to the equation that migrants will take into consideration both the wage differentials and the probability of employment, which together predict the expected earnings after migrating. Following from this is the assumption that in the absence of wage and employment differentials, migration will not occur, and that the size of the differentials determine the size of the migration flows. Thus, both individual level and structural level neoclassical economic migration theory predict that migration will move in accordance with the levels of wage differentials or the combination of wage and employment differentials. However, in terms of data availability and applicability micro data are harder and more costly to obtain than macro data. Information on individual preferences and characteristics can best be obtained via interviews or surveys, which is a time consuming and costly endeavor, whereas it is relatively easy to collect data on average income and unemployment rates per country.

In addition to the assumptions of the neoclassical economic micro variant the New Economics of Migration Theory variant was introduced in the 1980 s to deal with the fact that most decisions to migrate are not made by individuals acting as independent actors. This theory proposes that rather than isolated individuals, the entire ${ }^{13}$ Massey et al. (1993), pp. 434 
household should be regarded as the unit of analysis 14 Thus, new economics of migration theory proposes an argument of mutual interdependence. It is based on the assumption that all the members of the household want to minimize the risk to their family income, therefore they diversify the "allocation of resources" 15 Some family members can work in the local economy, while others can migrate to collect income abroad. In this case, if the economic situation in the home country deteriorates, the family can still rely on income from family members that migrated, thus diversifying their total risk. I would argue that the new economics of migration theory is another variant of the theories based on the idea that was initially put forward by neoclassical economic migration theory and is based on the assumption that actors make rational cost benefit calculations. Both the micro variant of neoclassical economic migration theory and the new economics of migration theory based on human capital are based on micro-level decisions ${ }^{16}$ In this thesis, when trying to establish the link between economic parameters and migration flows, the focus will be on the available and generally accepted measures of income and unemployment differentials ${ }^{17}$

Distinctly different is the Dual Labor Market Theory, which does not at all emphasize the decisions made by individuals, but is based on the idea that migration is caused by "the demands created by modern industrial societies." 18 Building on Kurekova.19 World Systems Theory is based on a similar notion, namely that globalization of capital and labor markets drive migration because of the desire for lower wages and

\footnotetext{
${ }^{14}$ Kurekova (2011), pp. 7

${ }^{15}$ Massey et al. (1993), pp. 436

${ }^{16}$ Either by the individual or the household.

${ }^{17}$ These measures will be elaborated upon in the Data section.

${ }^{18}$ Massey et al. (1993), pp. 440

${ }^{19}$ Kurekova (2011), pp. 9
} 
higher profits, and therefore migration is an "inevitable consequence of capitalist development."20 Even though this is an interesting perspective to consider, it is almost impossible to measure. The majority of migration theories are based on the assumption that economic parameters and market forces are variables that are considered by migrants when they make the decision to migrate based on rational calculations.

To get a better understanding of the causes of migration we also need to understand the importance of the perpetuation of international migration. As soon as migrants settle in one area or country, other migrants are more likely to decide to move to this area than to a different area. One of the theories that deals with this phenomenon is Network Theory. This theory seeks to explain why migration continues even if wage and unemployment differentials equalize $\ell^{21}$, namely via diaspora networks that form in countries or specific regions when migrants settle. These networks have the potential to shape the destination's country's "social, cultural, economic and institutional conditions" 22 Again, this theory focuses on the role of individuals or groups of individuals establishing network connections. Network theory posits that once the number of migrants in a particular region reaches a certain threshold, the costs and risks of migration will decrease substantially for other migrants, who will then be more likely to settle in this region.

A paper by Leblang et al.23 focuses on migrant networks and their role in the ${ }^{20}$ Massey et al. (1993), pp. 445

${ }^{21}$ Kurekova (2011), pp. 10

${ }^{22}$ ibid., pp. 10

${ }^{23}$ Leblang, D., Fitzgerald, J., Teets, J. (2007) "Defying the Law of Gravity: The Political Economy of International Migration" 
perpetuation of migration flows. They present two main arguments. First, the existence and the size of the migrant networks in the destination country are essential to understanding the perpetuation of migration flows. Second, there are several other economic and political factors that can potentially influence migration. Both arguments do not contradict what has been previously stated in this thesis, namely that network theory can potentially partly explain migration flows but that other economic and political explanations should not be disregarded. However, Leblang et al. also argue that it is useful to study migration flows in a large sample with many countries of origin and destination, instead of focusing on a particular destination, in order to be able to generalize findings. By focusing on a particular destination country we cannot easily generalize. However, we do have the opportunity to study migration developments in great detail, and learn about migration on a smaller scale ${ }^{24}$ and from this we can assess how we can extrapolate these findings to a larger scale. Other studies have also investigated the importance of networks for migration. A paper by Munshi25 tries to identify job networks among Mexican migrants, and investigates what the effects of networks are on the likelihood of employment. Their findings indicate that an individual is more likely to find a job if his network of co-nationals is larger.

Having established that migrant networks can potentially explain part of the incentive to migrate, the following question needs to be answered: what exactly are

\footnotetext{
${ }^{24}$ From a small number of countries to several regions

${ }^{25}$ Munshi, K. (2003) "Networks in the Modern Economy: Mexican Migrants in the U.S. Labor Market"
} 
migrant networks? In his paper, Spitte ${ }^{26}$ proposes the following definition of migrant networks: "recurrent sets of interpersonal ties that bind migrants and non-migrants together that can be drawn upon to facilitate entry, adjustment and employment at the destination." 27 Thus, migration networks are some kind of structure in the destination country that bind migrants and potential migrants with the same nationality. When these networks reach a certain size, it becomes more attractive for potential migrants to move to the country or region where this network is located and we expect to observe larger migrant flows to the regions where other co-ethnic migrants have located. Dolfin et al. ${ }^{28}$ investigate the mechanisms by which networks can exert their effect on migration movements. They identify several potential benefits of migrant networks, including information on how to cross borders and information on employment opportunities, thus providing information about jobs at the destination.

The major challenge that needs to be faced however, is how those migrant networks can be measured. Several measures are already available that have been proposed by existing literature, such as the size of the migrant stock 29 or using survey data and measuring migrant networks as "the proportion of sampled individuals that are located at the destination in a given year." 30 The Sample and Data section will describe in more detail how these migrant networks can be quantified.

\footnotetext{
${ }^{26}$ Spittel, M. (1998) "Testing Network Theory through an Analysis of Migration from Mexico to the United States"

${ }^{27}$ ibid., pp. 1

${ }^{28}$ Dolfin, S., Genicot, G. (2006) "What do Networks Do? The Role of Networks on Migration and 'Coyote' Use"

${ }^{29}$ Leblang et al.(2007)

${ }^{30}$ Munshi, K. (2003)
} 
This thesis will not be able to explicitly tease out whether migrants move to certain Bundesländer because of the establishment of networks, or whether the networks were a result of migrants moving to areas where wages were high and unemployment was low. Although this study will not be able to be able to establish the sequence and thus the causality of these events, I do hypothesize that migrants from one sending country are more likely to migrate to regions were other nationals from their country were attracted to. Thus, we expect to observe for instance nationals from Poland to 'flock together' and move to certain areas that are relatively economically attractive, while staying together and forming Polish communities. Network Theory might one of the possible explanations for why we observe that nationals from the different Eastern European countries move to different regions within Germany regardless of economic differentials. This will be elaborated upon further in the Data and Empirical Analysis sections.

\subsection{European Migration}

The rest of this section will be focused on migration in the European Union and migration to Germany in particular. Towards the end of the 1990s, and especially in the years running up to the accession of the New Member States in 2004, the issue of labor migration has risen to the top of the EU policy agenda. The barometer study ${ }^{31}$ conducted by the European Foundation for the Improvement of Living and Working Conditions collected data on the migration intentions of European citizens.

\footnotetext{
${ }^{31}$ Fouarge et al. (2007) "Factors Determining International and Regional Migration in Europe"
} 
Even though migration intentions do not directly translate to actual migration flows, it is interesting to take a look at the results of the survey as an indication of what could be considered to be important predictors of migration. The main findings regarding migration intentions among EU citizens are that the intention to migrate is reported more often when the expected returns of migration are high, when the migration distance is short and the economic prospects in the home country are bad. These are all rational and financial variables. Interestingly, the study also found that demographics of potential migrants play a role. For instance, they found that younger inhabitants are more likely to migrate ${ }^{32}$ Furthermore, singles and people without children were also more inclined to migrate. Another interesting finding is that previous positive experiences with job related migration increase the likelihood of migrating, and a positive perception of migration in general also increases migration incentives. However, these variables can only be measured using survey data that needs to be collected each time the circumstances change. Even though such surveys might have the potential to incorporate more factors that determine migration flows, the simplicity of a macroeconomic model has many advantages.

\subsection{East-West Migration}

Now we will shift focus from determinants of migration in the European Union to migration from Eastern to Western Europe. The rest of this section will be devoted to discussing the theoretical basis of Eastern European migration research and the most

${ }^{32}$ Fouarge et al. (2007) "Factors Determining International and Regional Migration in Europe", pp. 7 
important findings and questions regarding European migration flows. Kurekova 33 discusses the theoretical basis of Central and Eastern European migration research. In her paper she discerns two main approaches to migration research, which were outlined previously: the approach based on economic parameters such as wages and income differences, and the approach that takes individual surveys as the basis. These two are two extremes on the spectrum. Other theories have tried to critique one of these approaches to fill in the gaps. However, most migration studies based on either the neoclassical theory of migration or the individual level approach have not been able to predicts migration flows accurately. The challenge to make accurate predictions not only depends on finding the 'perfect' theory, which includes all the variables that accurately describes and predicts migration flows, but also depends on the quality of available data. This will be elaborated further in the Argument section.

With the accession of New Member States in 2004 and 2007 the existing member states had the opportunity to apply for a 'transition agreement' to ensure that their labor markets would not be flooded with potential migrants from Eastern Europe. Kahanec et al ${ }^{34}$ discuss the impact of these transition arrangements on migration flows. Their study finds that there was an increase in the number of migrants going from the New Member States to the EU15 mainly to Ireland and the United Kingdom. This is thought to be the result of the transition agreements that were

\footnotetext{
${ }^{33}$ Kurekova (2011), pp. 18

${ }^{34}$ Kahanec, M., Zaiceva, A., Zimmermann, K.F. (2009) "Lessons from Migration after EU Enlagerment"

${ }^{35}$ All Member States before 2004.
} 


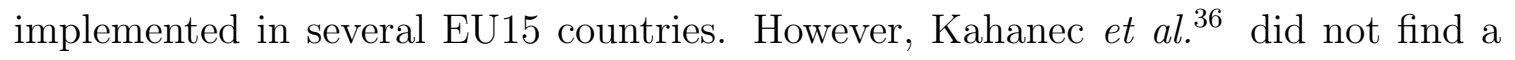
direct link between the labor market restrictions and migration flows, which is an important finding in the light of studying migration to Germany. Before the accession of eight New Member States in 2004, the existing member states had the possibility to opt for several transition periods 37 with a duration of two years, three years and two years subsequently. After each phase the existing member states could apply for an extension of the restrictions.

Initially, only the United Kingdom, Ireland and Sweden opened their borders to migrants from the New Member States. After the first two year phase several other countries decided to open their borders, including Spain, Portugal and Greece. Later these countries were followed by the Netherlands, Luxembourg, Italy, Finland and France. In 2009 Denmark and Belgium ended the restrictions. The last countries to lift the labor market restrictions were Austria and Germany, both in 201138 finally granting full access to their respective labor markets. One would logically expect a relationship between accessibility of labor markets and migration flows. There is an increase in the number of migrants from the New Member States to the EU15 countries after 2004 and 2007. This increase in migration flows was not evenly distributed across the EU15 countries. However, as was previously mentioned Kahanec et al. do not find "a simple link between the transitional arrangements and the post enlargement migration." 39 This serves as an indication of the fact that

\footnotetext{
${ }^{36}$ Kahanec et al. (2009)

${ }^{37}$ Brenke, K. (2011) "Labor Mobility in Central and Eastern Europe: The Migration of Workers to German Has Been Limited in Scope"

${ }^{38}$ Brenke, K. (2011)

${ }^{39}$ Kahanec et al. (2009), pp. 36
} 
migration is very complex and challenging to measure, and even though one would expect there to be some effect of completely opening the borders on migration, this might not be observable in the data. Even though Germany had these restrictions in place, migration flows to Germany can still be assessed because we are studying the differences between migration flows to destinations within Germany 40

Building on Bertoli et al. 41 who analyze the effects of the European Economic crisis and other institutional shocks on migration to Germany ${ }^{42}$ and find that a large part of the migration flows can be attributed to the fact that circumstances in alternative destinations were deteriorating at the time. They state the following about the importance of the diversion of migration flows as a result of macro economic shocks: "diversion effects are very large, as they account for 78 percent of the increase in migration flows to Germany". Bertoli et al. have studied diversion effects between 2007 and 2012. This finding underlines that economic parameters can have a significant impact on migration flow diversion, whereas policy changes as discussed by Kahane ${ }^{43}$ had less of a measurable impact on the diversion of migration flows. This finding is relevant because we need to take into account that migration flows to Germany may have been altered due to deteriorating conditions in alternative destinations. However, because the regions we are interested in are all located in one country one could argue that the exogenous shocks effecting the circumstances

\footnotetext{
${ }^{40}$ Also note that migration to Germany was restricted until 2011, while the timeframe of investigation of this study runs from 2000 to 2012. Furthermore, migration restrictions were faced by all the Eastern European New Member States, thus allowing us to assume the effects of migration restrictions were 'equaled out' across the different countries of origin.

${ }^{41}$ Bertoli, S., Brucker, H., Moraga, J.F.H. (2013) "The European Crisis and Migration to Germany: Expectations and the Diversion of Migration Flows", Forschungsinstitut zur Zukunft der Arbeit. ${ }^{42}$ Bertoli et al. (2013), pp. 3

${ }^{43}$ Kahanec et al. (2009)
} 
in theses regions will be distributed roughly in the same way. Therefore the problem of changing circumstances is less problematic for instance compared to studying the migration flows to different countries.

This section surveyed the main theories and main findings of migration literature in recent years, finding that the emphasis has moved from economic theories to more social-political theories that attempt to explain migration 44 When looking at migration in the European Union, and from Eastern European countries to Germany in particular, several developments cannot be explained sufficiently by existing migration theory. The rest of this paper will be devoted to developing the research design and will present the main findings. First, the main arguments and the methodology will be outlined, leading up to several testable hypotheses, followed by the empirical analysis, results and conclusions.

\footnotetext{
${ }^{44}$ Please refer to the Appendices for a summary of all the theories that were discussed and their main criticisms.
} 


\section{The Argument}

While the main goal of broader migration research is to construct a theory and come up with a set of variables that best capture the different aspects that explain and are able to predict migration flows, this paper tests the predictive value of economic parameters and migrant networks on the size of migration flows in the case of migration from Eastern European countries to the German Bundesländer during the first decade of the 21st century.

Germany has been selected as a destination country firstly because it attracts one of the highest numbers of migrants from Eastern Europe. What makes Germany unique are its convenient and central geographic location, and its historic ties with the Eastern European region. Furthermore, historically many people from Eastern European have been regularly exposed to and have quite detailed knowledge of the German language. Thus, not only does Germany offer a relatively close and somewhat familiar destination, it is also one of the richest and most successful economies in the Eurozone. Germany can be considered Europe's "industrial powerhouse", and it played a tremendously important role in saving the European Union from falling back into recession after the economic crisis in 2008. Because of its booming economy Germany has been very attractive for migrants from all over and outside of Europe, thus making it a very relevant and important country to study. The German Statistical Agency and German Federal institutions have been collecting a tremendous amount of very accurate and detailed migration data, both at the country as well as 
the state 45 level, which is easily accessible and can be used to study migration flows to the different regions within the country, which is quite unique.

When looking at the literature, quite a bit has been written on migration within Germany after the reunification of the country. Building on the findings of Heiland 46 who investigates recent trends in the migration from East Germany to West Germany between 1991 and 2002 and finds that the regions that experienced the largest rates of outmigration to the West include Thüringen, Sachsen and Sachsen-Anhalt 47 and the most popular regions are the larger and more industrial provinces of BadenWürttemberg, Bayern, Nordrhein-Westfalen and Niedersachsen. In the East, Berlin remains a popular destination. Heiland too, uses unemployment rates and wages by region to correlate them with migration patterns, and finds that there is "a relatively stable ordering over time that is consistent with the outmigration distribution pattern.' 48 These findings illustrate that we indeed need to verify whether this is also applies for migration from Eastern European countries to the different Bundesländer. We would expect that as the differences in income and unemployment increase, that migration increases, and that regions in Germany that offer more favorable economic conditions, will attract more migrants.

In previous sections, we established that economic prosperity is a potentially important driver of migration from East to West. However, the role of networks should not be underestimated. The power of migrant networks is that they provide more

\footnotetext{
${ }^{45}$ State refers to the German Federated States (Bundesländer)

${ }^{46}$ Heiland, F. (2004) "Trends in East-West German Migration from 1989 to 2002"

${ }^{47} i b i d .$, pp. 176

${ }^{48}$ ibid., pp. 185
} 
information, safety and make the transition to a new country, language and culture more accessible and smoother. This will be elaborated upon in more detail in the Hypothesis section, but generally speaking the expectation is that initially migrants will be more likely to settle in regions that offer relative economic benefits, but once a certain threshold has been reached, migration to this area will be considered more attractive because of the established migrant networks, and thus will attract more migrants relative to other regions. The literature is divided roughly into two camps, namely that of the economic theories and that of network theory. The previous section has argued that these two theoretical approaches should not be regarded as two mutually exclusive theories, but rather as two different positions on a sliding scale. The theories based on economic parameters place more emphasis on the economic incentives for migration, while the migrant network approach emphasizes that established network of migrants of the same nationality can lower the costs of migration 49 thus providing an incentive to migrate.

This thesis aims to investigate three questions. First, whether migrants from the New Eastern European Member States are distributing themselves differently across the German Bundesländer. Second, whether these migration patterns can be sufficiently explained by existing migration theory. And finally, whether there are better options available to measure migrant networks. ${ }^{50}$

\footnotetext{
${ }^{49}$ Including social, cultural and psychological costs

${ }^{50}$ This will be discussed in the Conclusions and Implications section.
} 


\section{Testable Hypotheses}

As was discussed in the Theory section of this paper, the migration literature has been heavily focused on neoclassical economic theory. However, recently a new scholarship has been developed that investigates other causes of migration, and gives insight in the reasons for selecting certain destinations. This "new economics of migration" also considers factors not directly related to the labor market, and also considers the effects of certain groups, such as households or families, as decision making units. Scholars that contribute to this debate seem to favor either individual rational and economically based theories or fall into the camp of those who consider migration to be a result of social, political and emotional decisions.

In this paper it has been argued that these two approaches should actually be regarded as two sides of the same coin. The arguments put forward in this and the previous section yield three testable hypothesis concerning the effects of economic parameters and the establishment of migrant networks on migration.

\subsection{Hypotheses}

Hypothesis 1: Economic parameters. Relative differences in economic parameters, wages, unemployment or both, will increase flows of migration from East to West.

Based on previous research we will investigate to what extent the economic situation

\footnotetext{
${ }^{51}$ Massey et al. (1993) "Theories of International Migration: A Review and Appraisal"
} 
in the German Bundesländer is correlated with the number of migrants from the New Member States moving to the respective Länder, and whether fluctuations in the relative wages and relative unemployment rates are associated with fluctuations in outmigration from the Eastern European New Member States to the different regions within Germany. Based on the extensive research that has been done in this area, it is expected that for Germany, there will also be a positive relationship between the size of the economic differentials and the number of migrants. This will be investigated both for Germany as a whole, and for the respective Bundesländer.

Hypothesis 2: Network effects. Migrant networks alter the flow of migrants, despite economic circumstances in other regions.

Migrant networks alter the flows of migrants to different regions within a country. Therefore we will investigate whether there are any patterns in outmigration from the New Member States to specific regions in Germany, and we will attempt to identify variables that can serve as a measurement of Migrant Networks. These different measurements will be discussed in the Sample and Data section, such as the stock of migrants 52 It is expected that it is more difficult to find an accurate measure of migrant networks then it is for the well established economic variables. However, we still expect to find a relationship between migrant networks and flows of migrants, which will be able to explain an important part of the variation in migration flows.

\footnotetext{
${ }^{52}$ As opposed to the flow of migrants.
} 
Hypothesis 3: Network effects and Economic parameters. Network effects and economic parameters, taken together, yield a more accurate prediction of migration flows to the German Bundesländer.

In order to test this hypothesis both economic variables and migrant network variables will be included in the analysis, to assess whether a combination of both variables is able to explain more of the variation in migration flows from the East to the German Bundesländer. However, by adding more and more variables to the model we are guilty of just throwing things in 'the kitchen sink. 53 However, in this case there is strong theoretical basis to believe that both economic parameters and migrant networks have an impact on migration flows, and therefore it is useful to see whether combining these different groups of variables will lead to more explanatory power.

The hypotheses and relationships described above imply that we are looking for a causal relationship, but this needs further clarification. In order to establish causality it needs to be made sure that we can observe 'temporal precedence' 54 Also, the cause and the effect need to be related, i.e. there needs to be covariation between the cause and the effect. To establish whether and how cause and effect are related we need to do a correlation analysis of the economic variables and migration flows, and migrant network variables and migration flows, respectively. Figure 1 displays the proposed correlation analysis.

\footnotetext{
${ }^{53}$ By adding more variables to the model, it might explain more of the variation in the data, but does not clearly distinguish between the effectiveness of one group of variables based on economic parameters versus another group of variables based on migrant network variables.

${ }^{54}$ I.e. show that the cause occurred before the effect and not the other way around.
} 


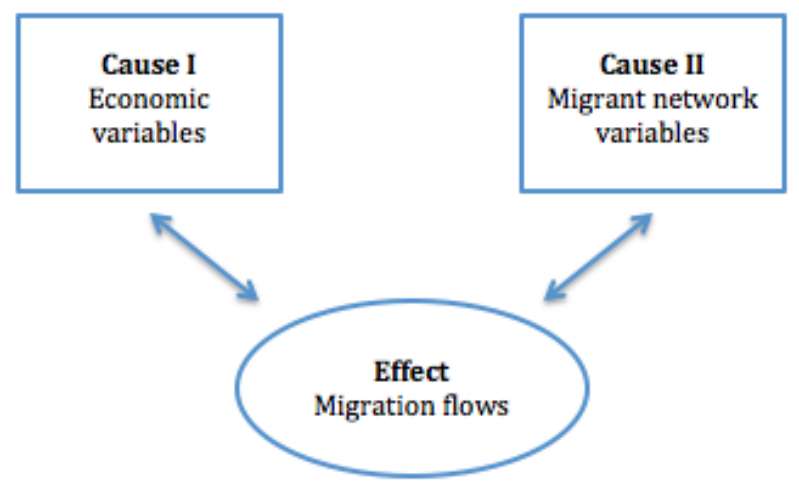

Figure 1: Proposed correlation analysis

Both correlations are expected to be positive; increasing economic differentials will increase migration, and as the size of migrant networks increase the flow of migrants is likely to be directed towards the location of these networks.

\subsection{Selection Effects and Ideal Experiment}

Unfortunately, we cannot conduct an experiment where we randomly assign subjects to a treatment group and a control group. The fundamental problem of causal inference is that one unit cannot be assigned to treatment and control at the same time, and the assignment to treatment and control is decided by the subjects themselves.

If we were to conduct an ideal experiment the dataset would consist of a group of countries which would randomly be assigned to one control group and three treatment groups. The control group will receive no signal of fluctuation in either economic parameters and changes in network parameters, and the treatment groups will include 


\begin{tabular}{ll}
\hline Group & Treatment \\
\hline Control group & No fluctuating economic or network parameters \\
Treatment group I & Fluctuating economic parameters \\
Treatment group II & Fluctuating network parameters \\
Treatment group III & Fluctuating network and economic parameters \\
\hline
\end{tabular}

Table 1: Ideal Experiment

countries that were only exposed to either fluctuations in economic circumstances, fluctuations in migrant networks or fluctuations in both, as displayed in Table1.

Furthermore, potential missing variables that could influence the analysis need to be identified and included in the analysis so they can be controlled. In the Theory section some exogenous variables were discussed that could potentially have impacted migration flows from Eastern Europe to Germany. For instance, it could be argued that the 2008 global economic crisis might have contributed to the increase in migration flows to Germany due to decreasing attractiveness of alternative destinations. Indeed, Bertoli et al $[55$ found that deteriorating economic conditions in alternative destinations account for a large part of the increase of migration from the Eastern European countries to Germany. How can this be dealt with? To begin with, we are studying differences between regions in the same country and not differences between different countries. So we need to be less worried about country-specific characteristics that drive migration if we want to investigate the differences between the regions. Of course, we need to be aware of characteristics that are unique to Germany, because they could be potentially confounding. However, extensive research has been done, and despite the fact that Bertoli et al. have found that diversion ${ }^{55}$ Bertoli et al. (2013) 
effects are an important driver of migration to Germany, they also conclude that "current economic conditions at origin are significant determinants of migration" 56 and are likely to lead to larger migration flows, in spite of diversion effects.

Pursuing this argument, when establishing that the main interest of this study are the regional differences between the Bundesländer and their respective migration flows, and focussing on the relative migration rates, factors that have an effect on the country level can be regarded as exogenous. If there is a factor that influences migration flows to different Western European countries 57 this impacts the entire sample that we are studying, which does compromise our ability to generalize to a large group of other regions or countries, but on the other hand allows us to study differences between regions and having to worry less about changes in those variables compared to when we would be comparing across countries.

To be certain the above mentioned argument about external effects of migration policies can be applied, it needs to be ensured that migration policies and regulations do not differ greatly among the respective Bundesländer. The website of the the German Bundestag provides information on the competencies of the German Federation and the Bundesländer ${ }^{58}$ The German Federal Republic consists of 16 Bundesländer, that together form the German Federal Republic. The Federal laws apply to all the Länder in the Federation, and laws designed in the Länder only apply to the respec-

\footnotetext{
${ }^{56}$ Bertoli et al. (2013), pp. 2

${ }^{57}$ For instance a potential diversion of migration flows away from Spain and Italy to Germany as a result of the economic crisis, or the potential diversion of migration flows away from Germany as a result of the restrictions on labor migration.

${ }^{58}$ German Bundestag website. "Competencies of the German Federation and the Länder", see References for online access.
} 
tive Länder. Also, the Land laws cannot conflict with the Federal law. According to Article 31 of German Basic Law: "Federal Law shall take precedence over Land law, to ensure equitable living conditions prevail throughout federal territory." 59 There are several fields in which the Federal government designs and upholds legislation, such as foreign policy, defense, citizenship and currency. Migration policy is also regulated at the level of the Federal government and therefore there are no significant differences between the Länder and their policies. A study on asylum and migration policies in Germany 60 provides more detailed information on specific migration policies. In sum, this report also confirms that the final responsibility for migrant policy lies with the Federal government. The most essential legislative reform in the last ten years was the introduction of the Immigration Act ${ }^{61}$ in 2004 and 2005, which placed the administrative enforcement at the level of the Bundesländer. In other words, the legislation concerning migration is the same in the entire country, but the executive responsibility lies with the Bundesländer.

Another advantage of studying migration from Eastern European countries to Germany is their geographic vicinity. Several studies, including Leblang et al. ${ }^{62}$ find that if there are no co-ethnic networks available, migrants are less likely to move from country A to country B as their geographic distance increases 63 Thus, the existing migration literature has established a link between geographic distance and

\footnotetext{
${ }^{59}$ German Bundestag website

${ }^{60}$ Schneider, J. (2012), Working Paper "The Organization of Asylum and Migration Policies in Germany", Federal Office for Migration and Refugees

${ }^{61}$ Schneider, J. (2012), pp. 5

${ }^{62}$ Leblang, D. et al.. (2007) "Defying the Law of Gravity: The Political Economy of International Migration"

${ }^{63}$ Leblang et al. (2007), pp. 22
} 
migration flows, and thus this should be considered as a potential third variable. Building on Leblang, other variables that are commonly added to analyses include the existence of a common language, the level of right wing support, the age structure of migrants, population size and several other destination dummies ${ }^{64}$

The variables migration flow, relative wage, unemployment and immigrant stock will be included in the analysis as was discussed extensively in preceding sections. It is expected that these variables have the largest effects on migration flows from Eastern Europe to the German Bundesländer. Other variables that will be included and are expected to have a somewhat smaller effect, or variables that we include as control variables, are support for right-wing parties in the respective Bundesländer, migration policy changes, geographical distance between origin and destination and a measure for urbanization of the different Bundesländer. Right wing party popularity will serve as a proxy for the political climate in the respective regions. The more popular right wing parties are, the less welcoming the political climate will be for immigrants, therefore, it is more likely to observe lower levels of migration to those areas where right wing parties are more popular.

Geographic distance is included in almost all the empirical analyses in the existing literature, however, in the case of migration to the Bundesländer this is probably less relevant because the differences in distance are so small. However, to make sure that this indeed a factor that does not influence migration decision, it will be included in

\footnotetext{
${ }^{64}$ Variables included in the analysis by Leblang et al. $(2007)$ : Migration flow $=$ Immigrant stock + Distance + No Common Language + No Colonial Heritage + Relative wage + Unemployment + Welfare State + Right Wing Support + Voting Rights + Jus Solis + Age Structure + Democracy + Civil War + Actual Policy + Policy Preference + log(population) + Destination Dummies + Trend + Error term. Leblang et al. (2007), pp. 17
} 
the analysis. Migration policy changes is a variable that tries to capture how policy changes might have effected migration flows. This is a dummy variable which will be coded 0 or 1 , depending on whether there was a policy change in a given year or not. Less relevant for this research since we are studying one country are variables such as whether there is colonial heritage, whether the destination region and the countries of origin are democracies and whether the destination country is a welfare state. In the case of Germany and the New European Member States the variable democracy is not included, because both Germany and all the New Member States are democracies. The complete regression equation will look like this:

\section{Migration flow $=$ immigrant stock + relative wages + unemployment + right wing support + immigration policy + geographical distance + urbanization Bundesländer $+\varepsilon$}

The next section will describe the sample and the data that has been collected to measure the above mentioned concepts, and the Empirical Analysis section will go into more detail concerning the actual analysis. The regression model needs to be estimated using fixed effects for each Bundesland to control for any time invariant Land characteristics that might drive observed correlations. 


\section{Sample and Data}

This section describes the sample of origin countries and destination regions included in the data analysis, and other data that has been used for the empirical part of this thesis to evaluate the hypotheses as stated in the previous section.

\section{$5.1 \quad$ Sample}

The sample of origin countries that has been included in the analysis is composed by all the New European Member States that have joined the European Union between 2000 and 2007, which include the Czech Republic, Estonia, Hungry, Latvia, Lithuania, Poland, Slovakia and Slovenia which became members of the European Union after the 2004 enlargement, and Romania and Bulgaria, who became members after the 2007 enlargement. Malta and Cyprus ${ }^{65}$ have been excluded from the sample because for this research we are interested in the migration from Eastern European countries to the different German regions. The sample of destination regions includes all sixteen German Bundesländer.66 The next section will provide a detailed description of the data that has been used in the empirical analysis of this paper.

\footnotetext{
${ }^{65} 2004$ enlargement.

${ }^{66}$ Baden-Württemberg, Bayern, Berlin, Brandenburg, Bremen, Hamburg, Hessen, MecklenburgVorpommern, Niedersachsen, Nordrhein-Westfalen, Rheainland-Pfalz, Saarland, Sachsen, Sachsen-Anhalt, Schleswig-Holstein and Thüringen.
} 


\subsection{Migration Data}

The data on migration flows from the Eastern European New Member States to Germany and the respective German Bundesländer was made available by the Federal Statistical Office Germany ${ }^{67}$, The Statistical Office serves as an important advisor to the German Parliament, the Federal Government, embassies and other federal authorities 68 The Federal Statistical Office reports annual data on the migrant flows by country of origin to Germany and the respective Bundesländer. These migration figures are based on the numbers registered at the municipal level.

In Germany registration with the municipality became mandatory when a law was passed in 2002, which states that each individual is obliged to inform the municipality of any changes in residency ${ }_{69}^{69}$ The municipal registration makes a distinction between German inhabitants and foreign citizens, where foreign citizens are defined as "all people not possessing German citizenship". Germans that return from living abroad are registered as German citizens. The fact that immigrants are obliged to register with their municipality has several advantages. As a result of the law passed in 2002 migrants have a strong incentive to register with the municipality, and registration is required in order to obtain a work permit. Municipalities have an incentive to update their population registers regularly because municipal tax revenue is deponent upon the number of registered inhabitants. Therefore, the data collected by the Federal

\footnotetext{
${ }^{67}$ Located in Wiesbaden, Bonn and Berlin. Website: <https://www.destatis.de>

${ }^{68}$ Retrieved from: < https://www.destatis.de/EN/AboutUs/AboutUs.html>

${ }^{69}$ For more information on the data collection, see References for online access on Data Collection.
} 
statistical agency is very likely to accurately depict the number of migrants 70

The variable rel_migflow (relative migrant flow) is defined as the annual number of migrants from the different countries of origin that moved to the respective Bundesländer as a percentage of the total number of migrants that moved to Germany.

For example:

\section{Relative Migration Flow = $\frac{\text { Number of Polish migrants moving to Hamburg in year } t}{\text { Number of Polish migrants moving to Germany in year } t} * 100 \%$}

Notice that this is a measure for the relative migration from the Eastern European countries to Germany and its Bundesländer, and not the absolute number of migrants. Looking at relative migration allows us to compare across countries and Bundesländer and gain insight in the differences in outmigration from the countries of origin, and the different rates of migration to the German Bundesländer.

\subsection{Economic parameters}

The data on the economic parameters for this study were collected from the EUROSTAT database, which includes data on absolute annual GDP per capita and also GDP per capita corrected for purchasing power. More specifically, EUROSTAT has recorded data on the GDP of inhabitants of all the European member states from 2000, including information on the different regions within these European countries.

\footnotetext{
${ }^{70}$ The German migration data provided us with 1,920 observations, from 10 countries of origin, 16 destinations and 12 years of data recording.
} 
This also includes the 16 German Bundesländer, even broken down for several major cities within these Länder 70

This dataset also provides information on the total GDP in millions of Euros and the GDP per capita corrected for purchasing power with the the EU28 average GDP as a baseline. In this research the GDP per capita Purchasing Power Standard, which is recorded annually, will be used. The Purchasing Power Standard 72 serves as an indication of the relative purchasing power of a currency. The PPS is defined as such that one unit of PPS could theoretically buy the same amount of goods and services in different countries. Therefore, the GDP per capita corrected for purchasing power allows us to compare across countries and regions. From the GDP per capita corrected for purchasing power the variable rel_gdp (relative GDP) will be calculated, by subtracting the average GDP corrected for purchasing power of the country of origin from that of the different Bundesländer. For example:

\section{Relative GDP = GDP per capita Purchasing Power Standard for Poland in year $t$ - GDP per capita Purchasing Power Standard for Hamburg in year $t$}

If this variable has a negative value this indicates that the GDP per capita corrected for purchasing power in the country of origin is lower than that in the destination region. Likewise, if this variable has a positive value this implies that the GDP per capita in the country of origin exceeds that of the destination region.

The EUROSTAT database also provides similar detailed information for the un-

\footnotetext{
${ }^{71}$ EUROSTAT data on GDP, see References for online access.

${ }^{72}$ EUROSTAT Statistics Explained. See References for online access.
} 
employment rates in the Eastern European New Member States and the German Bundesländer. In this dataset the unemployment rate is defined as "the percentage of unemployed persons aged 15-74 in the economically active population". It also provides information on unemployment rates specified by sex and age, and the long term unemployment shares 73

For the purpose of this research the variable rel_unemp (relative unemployment rate) is defined as the difference between the unemployment rate of the working population between the countries of origin and the destination regions. The relative unemployment rate is obtained by subtracting the unemployment rate in the country of origin from the unemployment rate in the destination region. Thus, if this variable takes on a negative value the unemployment rate in the country of origin is lower than the unemployment rate in the destination region, and vice versa. If the variable has a positive value we expect to observe an increase in the flow of migrants to the designation region, where unemployment rates are lower than in the country of origin, thus providing positive economic prospects for migrants in the destination region.

\subsection{Migrant Networks}

The dependent variable and economic parameters as described in the preceding section are relatively easy to obtain and involve some minor calculations, and their effectiveness to reflect the phenomena that we are trying to measure has been tested

\footnotetext{
${ }^{73}$ EUROSTAT data on Unemployment, see References for online access.
} 
extensively in the existing literature. Relative wage differences are well captured by GDP per capita when corrected for purchasing power across countries, and unemployment rates serve as an accurate depiction of the estimated probability of success on the labor market for migrants. Measuring migrant networks is a lot less straightforward. Several suggestions have been made in the literature that were previously discussed. In sum, one can either opt for surveys to obtain information on the size of networks and their effects on the likelihood of migration, 74 or use data on the variation in migrant stocks as an indication of the size of co-ethnic networks. Surveys allow the researchers to obtain detailed information on individual characteristics of migrants such as their age, sex, education, type of work, factors they consider when making migration decisions, previous experience with migration and to gain insight in the history of migration, the frequency, duration and the number of migrants that return to their country of origin.

Clearly, information with this level of detail will enable researchers to investigate the relationship between the size and location of networks and the fluctuations in the propensity to migrate quite accurately. However, there are several drawbacks to this approach. First, it is expensive and time-consuming to collect and analyze a large number of surveys. Second, it is very hard to generalize from individual level data to general trends. This also applies to any other theory. On the one hand, there needs to be a sufficient level of detail in order to be able to make accurate predictions and come up with credible explanations, but on the other hand the theory also has to be sufficiently general and therefore generalizable. Surveys are potentially

\footnotetext{
74 Zhao, Y. (2003) "The Role of Migrant Networks in Labor Migration: The Case of China", pp. 501
} 
very useful for investigating which variables most accurately measure the effects of networks and most likely provide a good measurement of migrant networks. Hover, it would be preferred to be able to move beyond survey data and establish a set of variables that can be measured more easily whilst requiring no individual survey data, where will will lose some of the accuracy but gain a lot in terms of accessibility and feasibility.

One of those proposed more general measurements is used by Leblang et al., in their paper investigating the causes of international migration, is the migrant stock which is defined as the "existence and size of a co-ethnic network as the proportion of the stock of foreign born from country $o$ residing in country $d$ to the total size of country o's population".75 To make inferences about the migrant stock in the German Bundesländer data from the German Federal Statistical Office, which also provided information on migrant flows to Germany, will be used. Measures of migrant stocks are easier and a lot less costly to obtain than survey data, and have proven to be quite good indicators of migrant networks. Furthermore, looking at migrant stocks allows us to gain insight into differences in time series data, because annual fluctuations in migrant stocks can be observed. Therefore the variable migstock (migrant stock) will be used in this research as a measurement of the networks that migrants establish in the different German Bundesländer.

As was mentioned previously, migration flows are defined as the number of migrants from Eastern European country $A$ moving to German region $B$ as a percentage of the total number of migrants moving to Germany on an annual basis. These ${ }^{75}$ Leblang et al. (2007), pp. 17 
relative migration rates allow us to compare across Bundesländer and compare where migrants from the different countries of origin choose to locate. Migrant networks on the other hand, need to capture the size of the migrant group relative to the population in the home country. These migrant stocks as a proportion of the home country population need to be calculated from the absolute number of migrants residing in the destination regions and the population in the respective home countries. Fortunately, after an extensive search and inquiry with the German Federal Statistical Agency it appears that there is a dataset available which contains information on the number of Ausländer (foreigners), their respective countries of origin and destination regions. These data are available for the time period between 1998 and 2013 and are recorded on an annual basis. The dataset even specifies the gender and the marital status of the migrants. ${ }^{76}$

It should be noted that this extreme level of detail and extensive data availability is absolutely unique, and has not been demonstrated in any other study thus far. Several sources such as the World Bank and the OECD databases do provide information on the annual stock of migrants by destination country but rarely report both origin and destination country, let alone report data on regions within the destination country. Thus, it is very fortunate that German federal institutions have kept such detailed records.

Building on Leblang et al. ${ }^{77}$ for the purpose of this research the variable migstock will be defined as the proportion of migrants from country $A$ residing in region $B$

\footnotetext{
${ }^{76}$ Statistisches Bundesambt Online Database: https://www-genesis.destatis.de/genesis/ online/data see Appendices for more detailed description of the data search.

${ }^{77}$ Leblang et al. (2007)
} 
to the total size of country $A$ 's population. Also, it needs to be taken into account that our predictions are based on the idea that size of the migrant network at time $t$-1 has an impact on the direction and size of migration flows at time $t$. Therefore, we need to regress the migrant stock at time $t$ - 1 on migration flow at time $t$. Thus, looking at the migrant stock in the data in 2001 this refers to the migrant stock at the end of 2000. The proportion of foreign born nationals is calculated as the total number of migrants from the country of origin residing in the destination region per 1000 inhabitants of the country of origin. For example:

\section{Migrant Stock in year $t-1=$ $\underline{\text { Polish migrant stock in Hamburg at the end of year } t} * 1000$ Total Polish population in year $t$}

This measure of migrant stock will be calculated for each country of origin, destination region and for each year. Based on the literature and hypotheses that were previously discussed, we would expect to see an increase in the number of migrants in regions where more migrants initially settled. Note that in this case the migrant stock is defined as the total number of migrants located in each Bundesland. However, the dataset also provides us with information on the gender and the marital status of the migrants. Investigating the composition of migrant networks is beyond the scope of this project, and unfortunately there is insufficient data in each cell thus making it less suitable for statistical testing. However, there are some interesting trends that can be observed.

According to the previously mentioned Eurobarometer study ${ }^{78}$ men migrate more

${ }^{78}$ Fouarge (2007) 
often than women, which can possibly be explained by the type of work that migrants do (typically low skilled) or by the fact that if one member of the household migrates it is more likely to be the woman that remains in the home country with the family. The dataset distinguishes between being single, married divorced, widowed, or the status is unknown 79 When taking a quick look at the data 80 it can be observed that when looking at the total number of migrants, more migrants who report their marital status as single than any of the other categories. Also, on average there are more male migrants, although there are some differences by country of origin. Interestingly, more men are reported as single and more women are reported to be married within their respective categories. Similar patterns can be observed when looking at the different Bundesländer. This indeed confirms the predictions about the expected composition of migrant networks.

\subsection{Other variables}

Right-wing support. The election results by Bundesland can serve as an indicator of a regions level of hostility towards foreigners. The higher the percentage of votes for the National Democratic Party of Germany (NPD) in the respective Bundesländer, the less welcoming this region will be considered to be for migrants. It is expected that greater support for this right wing party will be associated with lower migration flows. The federal elections that were within the range of this research's time fram ${ }^{81}$

\footnotetext{
${ }^{79}$ Translated from: ledig, verheiratet, verwitet, gescheiden, unbekannt.

${ }^{80}$ For instance for the migrant stocks in the popular destination region Baden-Württemberg at the end of the year 2000 .

${ }^{81}$ Between 2000 and 2012.
} 
were held in 2002, 2005 and 2009. The German Election Resources' website provide information on the absolute number of votes and percentages of votes specified for the different parties and at the level of the Bundesländ. ${ }^{82}$ However, in 2002 there were no right-wing parties of significant size that participated in the elections, therefore the results of the 2005, 2009 and 2013 elections will be used.

The results of the elections are recorded both for the first and the second votes. In Germany, the first vote allows a vote for a direct candidate from the constituency of the elector, and this candidate in turn will apply for a mandate in the Bundestag. The second vote is determined by distribution of the seats in the Bundestag. Hence, the voter votes for a party which will then propose a candidate that will take a place in the Bundestag. The results of the first vote are more informative for making comparisons across right wing party popularity between the Bundesländer since the first vote goes directly to a local candidate. Therefore, this analysis will use the results of the first votes as an indicator of right wing party popularity. One would expect that as overall wealth increases and unemployment rates decrease that negative attitudes towards migrants (as measured by right wing popularity) decrease, as migrants are less likely to be perceived as threatening for employment opportunities and wealth distribution. In the 2009 elections the NPD received between 1 percent in Hamburg and 3.5 percent of the votes in Thuringen in the first vote. This result is indeed in line with our expectations, since Hamburg has one of the lowest unemployment rates and highest annual GDP per capita, whereas Thuringen has higher unemployment rates and lower wages. Figure 2 illustrates the regional differences in right wing party

\footnotetext{
${ }^{82}$ Results German Federal Elections in 2005, 2009 and 2013. See References for online access.
} 


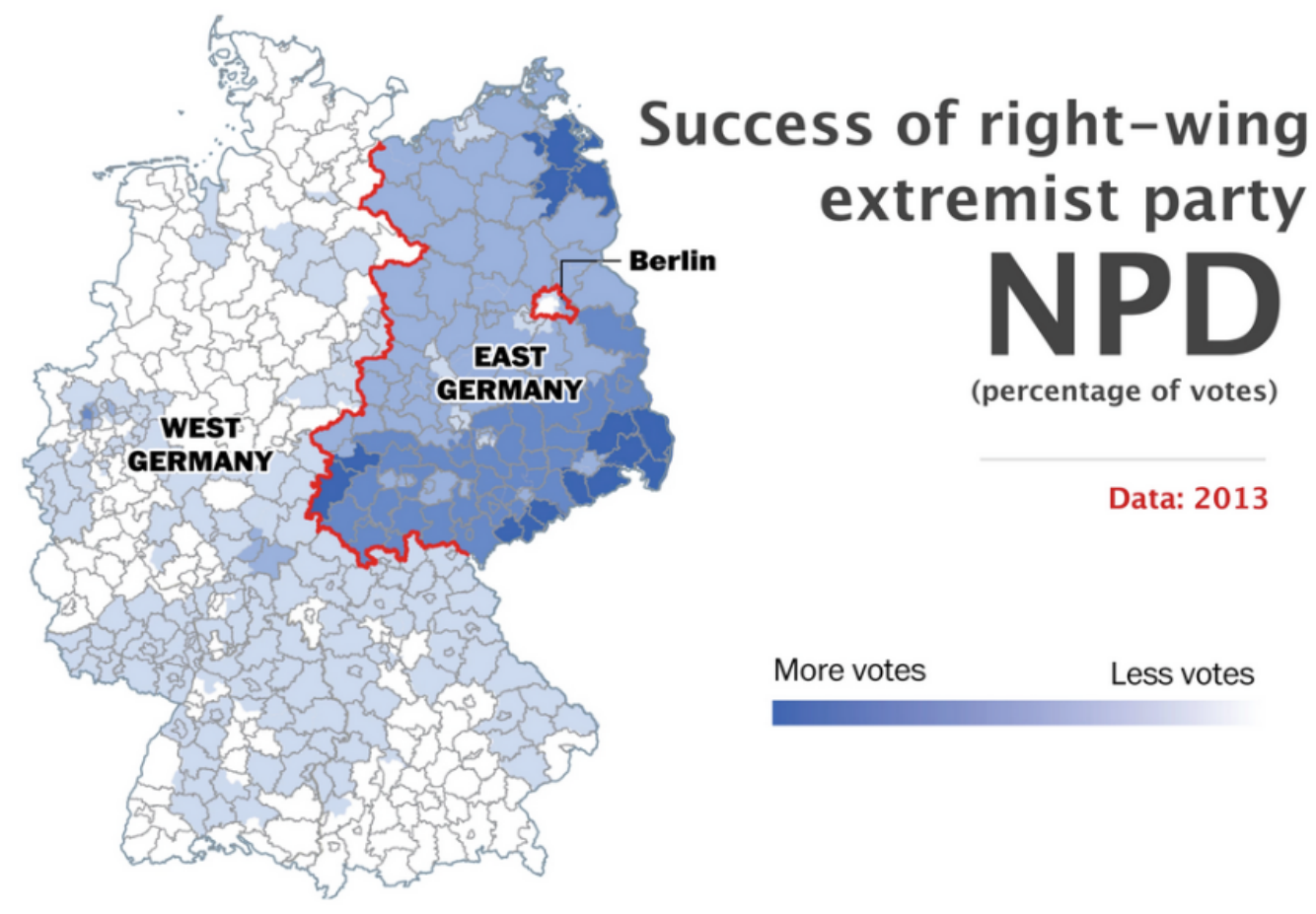

Figure 2: Right wing party popularity in 2013 elections.

popularity for the 2013 elections 83

Migration policy. For the purposes of this research, changes in migration policy that are expected to have an impact on migration are coded $\mathbf{0}$ for no change in migration policy compared to previous year and $\mathbf{1}$ for a change in migration policy compared to the previous year. When the mig_pol (migration policy) variable is coded as $\mathbf{1}$ it is expected that this is associated with a positive or negative change in migration flows. The Migration Integration Policy Index provides data on recent policy changes in

\footnotetext{
${ }^{83}$ Image from Washington Post, see References for online access.
} 
several countries, including Germany ${ }^{84}$ Such policy changes include the introduction of a language test for spouses that live abroad and want to move to Germany 85 which is expected to have a negative impact on migration, and the amendment of the nationality law which places a five year time limit on citizenship withdrawal as a result of fraud ${ }^{86}$ which is expected to have a positive impact on migration.

Geographical distance. The geographical distance between two different locations is most commonly measured as the great distance circle between two cities. In this case the great circle distance in kilometers between the capitals of the countries origin and the respective capitals of the Bundesländer ${ }^{87}$ will be calculated using an online tool ${ }^{88}$ The variable dist (geographical distance) is recorded as every possible combination of the distance between each Bundesland capital and each country of origin capital.

Urbanization. The size of cities relative to the population in the Bundesländer will be used as a measure of the degree of urbanization of the different destination regions. Migrants who are seeking employment are more likely to locate in areas in the vincinity of larger cities. Therefore, it needs to be taken into account that the size and number of cities in each Bundesland can potentially have an effect on the differences in migration flows. The World Bank Databas 89 measures urbanization as

\footnotetext{
${ }^{84}$ Migration Integration Policy Index: Country Profile Germany. See References for online access. ${ }^{85}$ Introduced in August 2007.

${ }^{86}$ Introduced in February 2009.

${ }^{87}$ Please refer to the Appendices for a list of all the capitals of the Bundesländer and the Eastern European New Member States.

${ }^{88}$ Great Circle Distance calculator, see References for online access.

${ }^{89}$ World Bank Data on Urbanization as a percentage of the total population of the area. See References for online access.
} 
the percentage of people living in urbanized areas in each country 90 . Unfortunately, such data is not available at the regional level. Therefore, the variable urban_perc is defined as the population size of each Land's capital as a percentage of the total population of each Bundesland, which somewhat approaches the urban ratios as used by the World Bank on the country level 91

\footnotetext{
${ }^{90}$ The "urban population" refers to all people living in urban areas as defined by national statistical offices. For this database it is calculated using World Bank population estimates and urban ratios from the United Nations World Urbanization Prospects.

${ }^{91}$ urban ratio $=$ size of capital of Bundesland $A$ / total population of Bundesland $A$.
} 


\section{Empirical Analysis}

To test the relative importance of economic and network variables, a Fixed Effects regression model will be used. Employing a fixed effects regression model using panel data allows us to compare across Bundesländer while controlling for any time invariant characteristics. The advantage of fixed effects regression versus Ordinary Least Squares regression is that by using panel data to observe changes in the dependent variable over time, it is possible to control for omitted variables that vary between the different cases but are constant over time. 92 Thus, using a fixed effects model allows us to make inferences about the 'within' variation in order to investigate whether a causal relationship exists.

This section aims to fulfill two objectives. First, to make a comparison between the different countries of origin and different destination regions and establish whether migration flows are distributed roughly equally across the destination regions. Second, to draw inferences about the relationship between the independent variables 93 and the dependent variable 94

Figure 3 displays the relative migration flows to the each Bundesland by country of origin between 2000 and 2012. Even though this figure does not allow us to clearly distinguish between the different countries of origin, it does provide a useful overview of the trends in migration flows by country of origin and destination region.

\footnotetext{
${ }^{92}$ Princeton University Data and Statistical Services, see References for online access.

${ }^{93} \mathrm{GDP}$ per capita, unemployment, migrant stock, right-wing support, urbanization, distance and migration policy.

${ }^{94}$ Relative migration flows form the Eastern European New Member States to the German Bundesländer.
} 


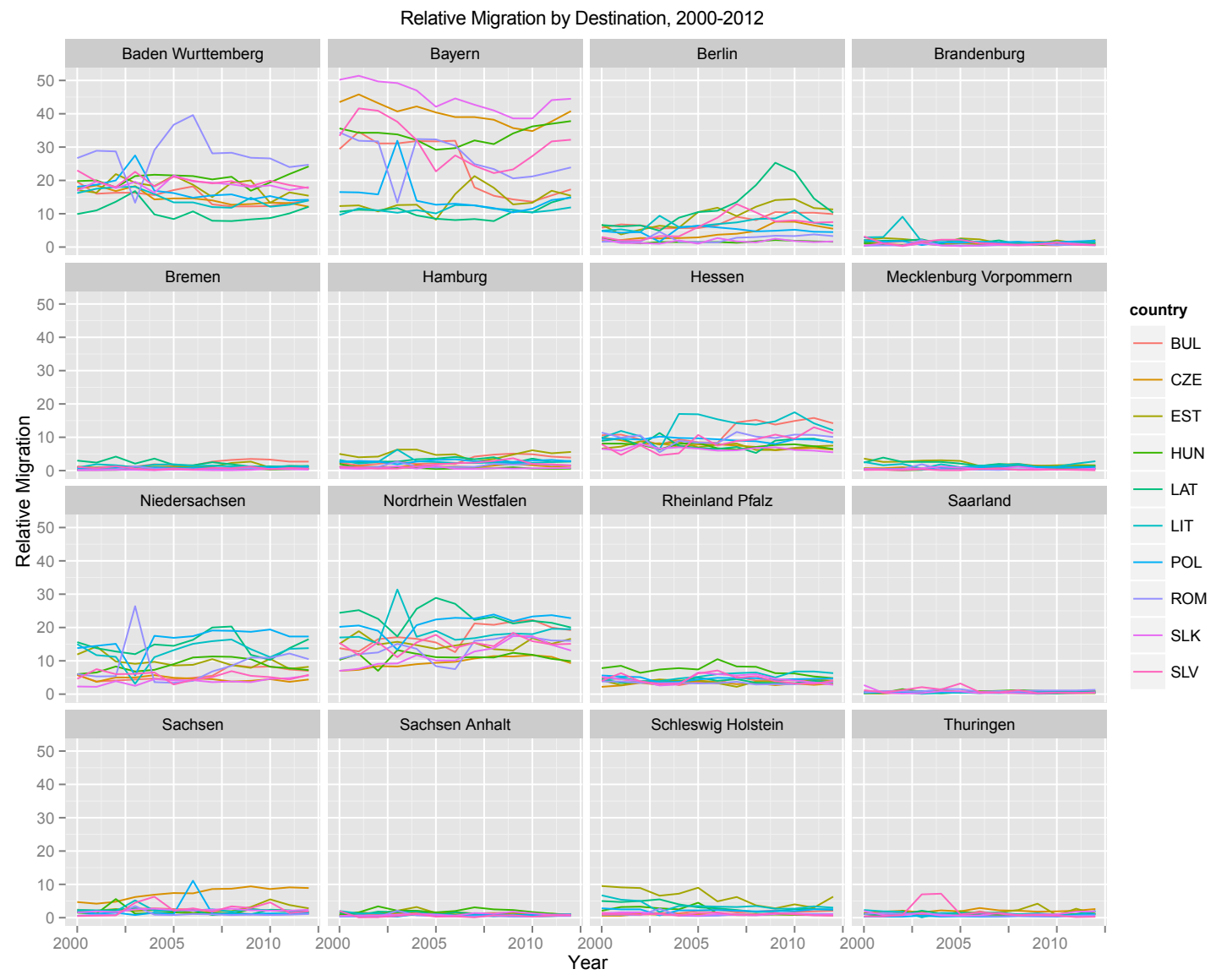

Figure 3: Migration flows by destination region and country of origin

In Figure 3, the panel for Bayern most clearly shows that rates of outmigration differ substantially between the countries of origin, and the relative flows are also higher than the migration flows to the other Bundesländer. To a lesser extent this is also the case for the relative migration flows to Baden-Württemberg. There is virtually no difference in the rates of outmigration to for instance Mecklenburg-Vorpommern, Schachsen-Anhalt and Saarland. We will examine the panels for Bayern and BadenWürttemberg more closely. 
The relative migration flows to Bayern and Baden-Württemberg by country of origin are displayed in Figure 4 and Figure 5. Hypothesis 2 predicted that the effects of migrant networks would alter the flow of migrants 'despite' economic differentials. Despite economic differentials refers to the prediction that when migrants are making a migration decision they are first and foremost looking at economic gains. If these gains are roughly equal across several destinations, potential migrants will also consider the presence of networks of co-nationals. When looking at the migrant stock data in more detail, it can be seen that the stocks of Slovakian migrants as a proportion of the total Slovakian population are the highest in Bayern throughout the twelve years that were observed in this study. Figure 5 shows that the highest relative flow of migrants to Bayern is from Slovakia. The lowest relative flows are from Lithuania and Latvia. Similarly, migration to Baden-Württemberg is characterized by high inflows from Romania, especially after 2004. The Romanian migrant stock is among the highest in Baden-Württemberg and Bayern.

Figure 6 shows boxplots of relative migration by Bundesländer. This figure clearly shows there is variation in outmigration to Baryern and to a lesser extent to Berlin. Similarly, figure 7 takes figure 6 and breaks it down by country. This graph compliments the first one nicely. Most of the boxes are narrow, indicating there is little variation over time. The pairwise plots displayed in figure 8 shows plots of the variables relative migration, relative unemployment and migration stock, without respect to the country of origin or destination region. The top row shows relative migration versus the three independent variables of interest. The strongest relationship appears to be between relative migration and migrant stock. 


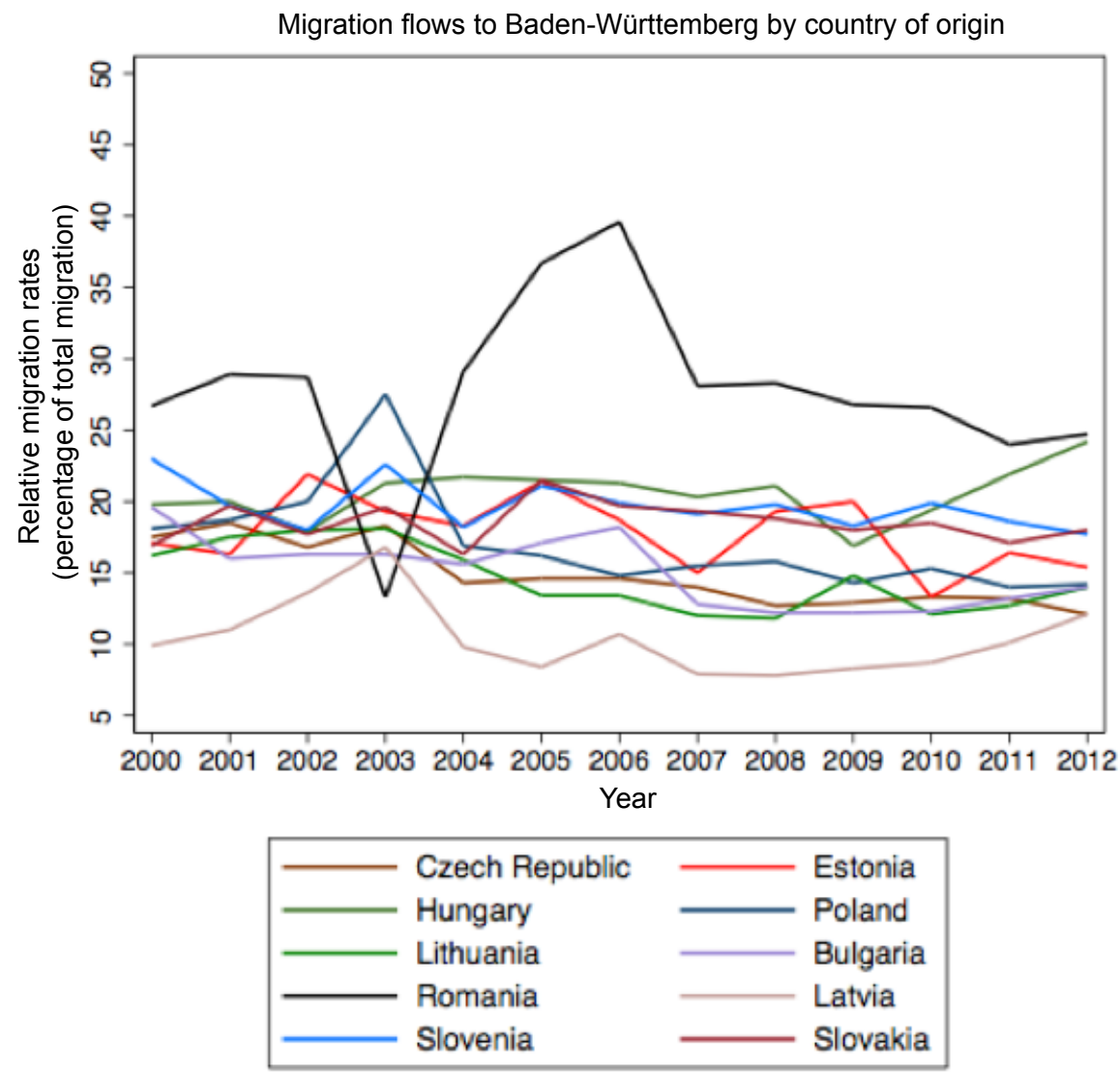

Figure 4: Relative migration flows to Baden-Württemberg by country of origin 


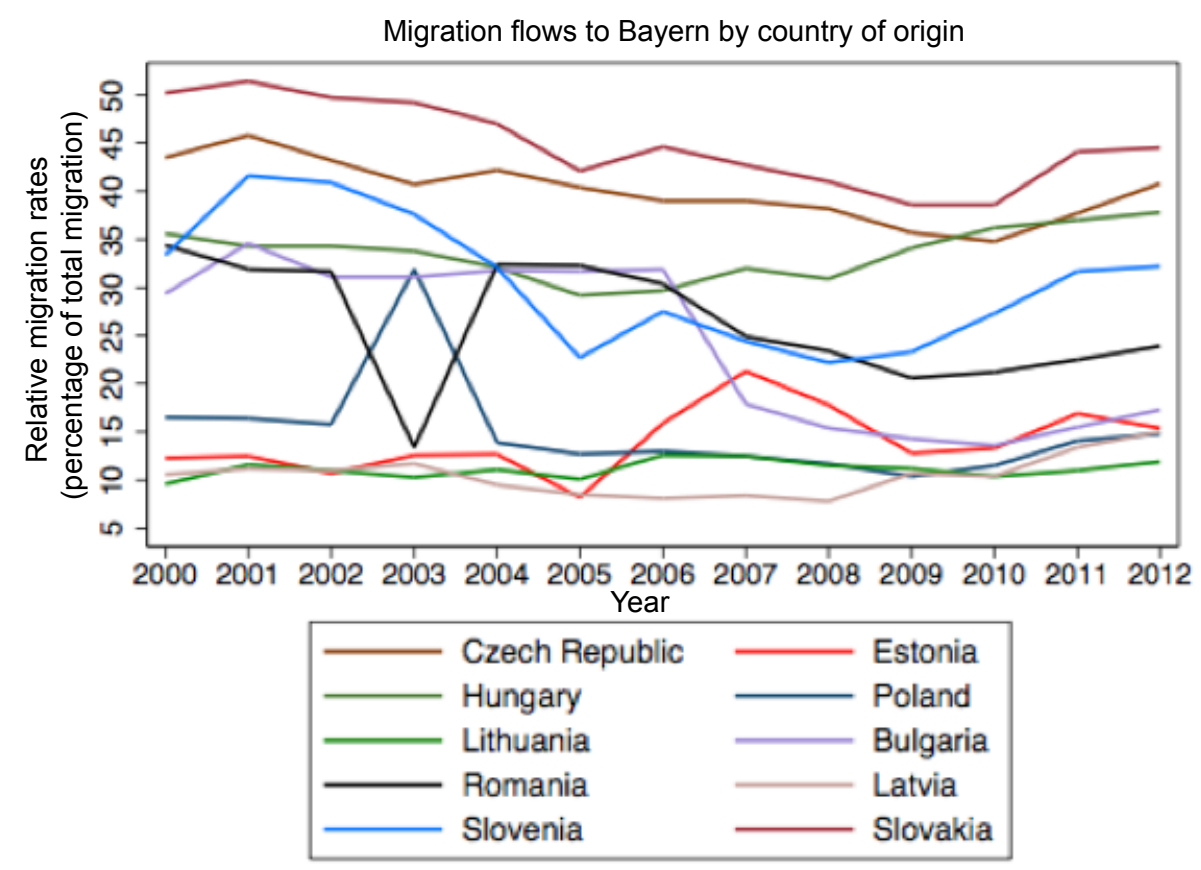

Figure 5: Relative migration flows to Bayern by country of origin 


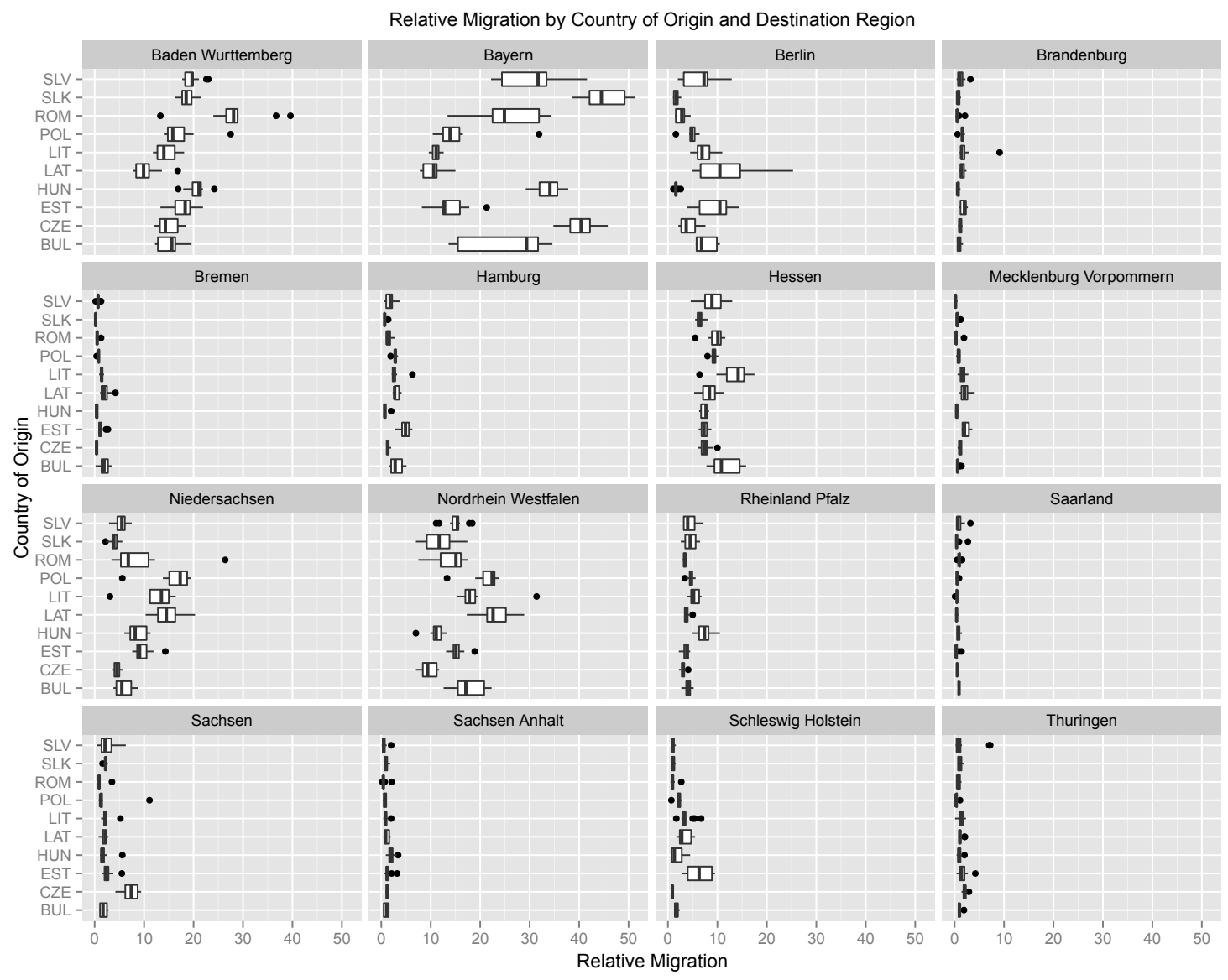

Figure 6: Boxplots relative migration by country by destination 


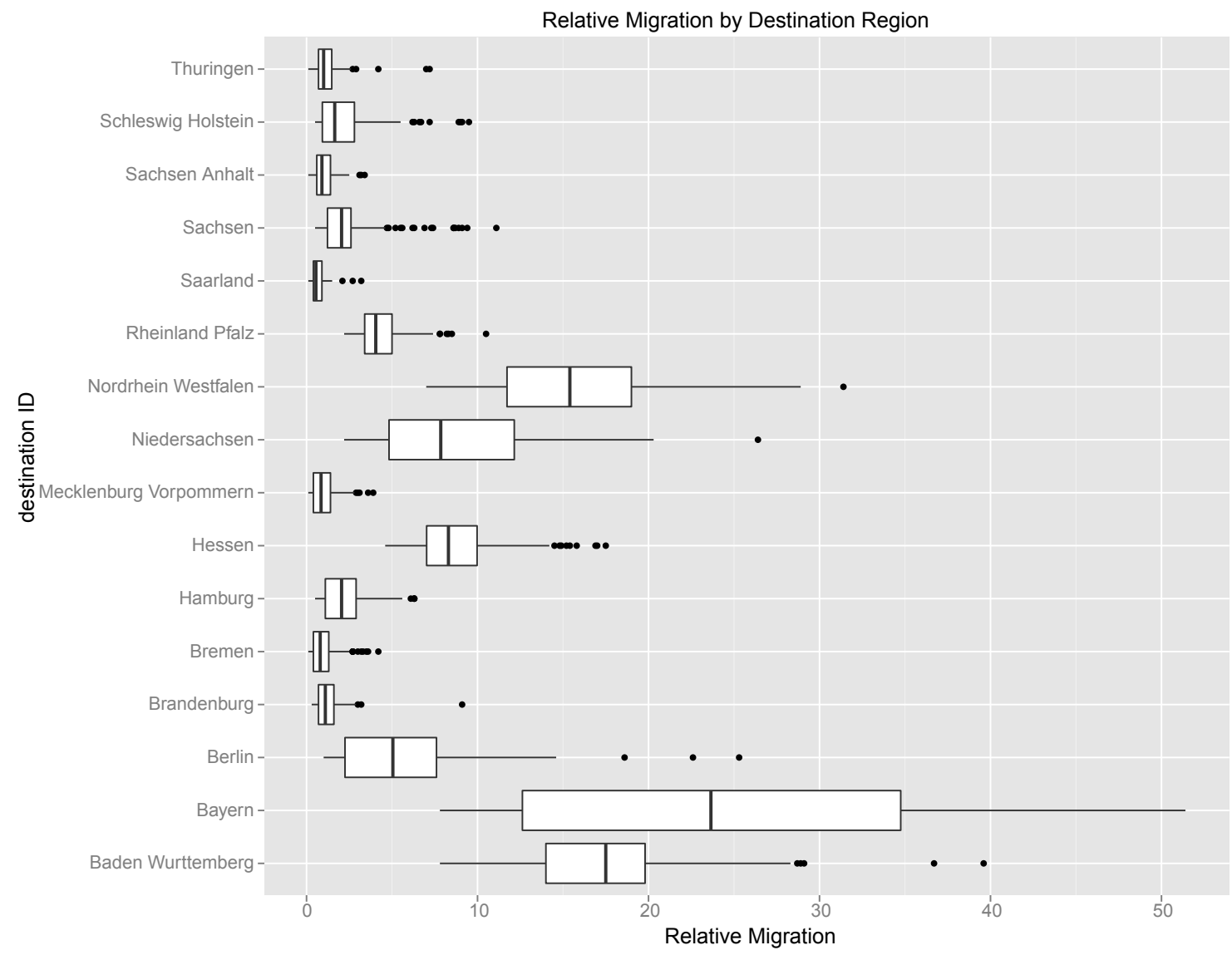

Figure 7: Boxplots relative migration by destination 


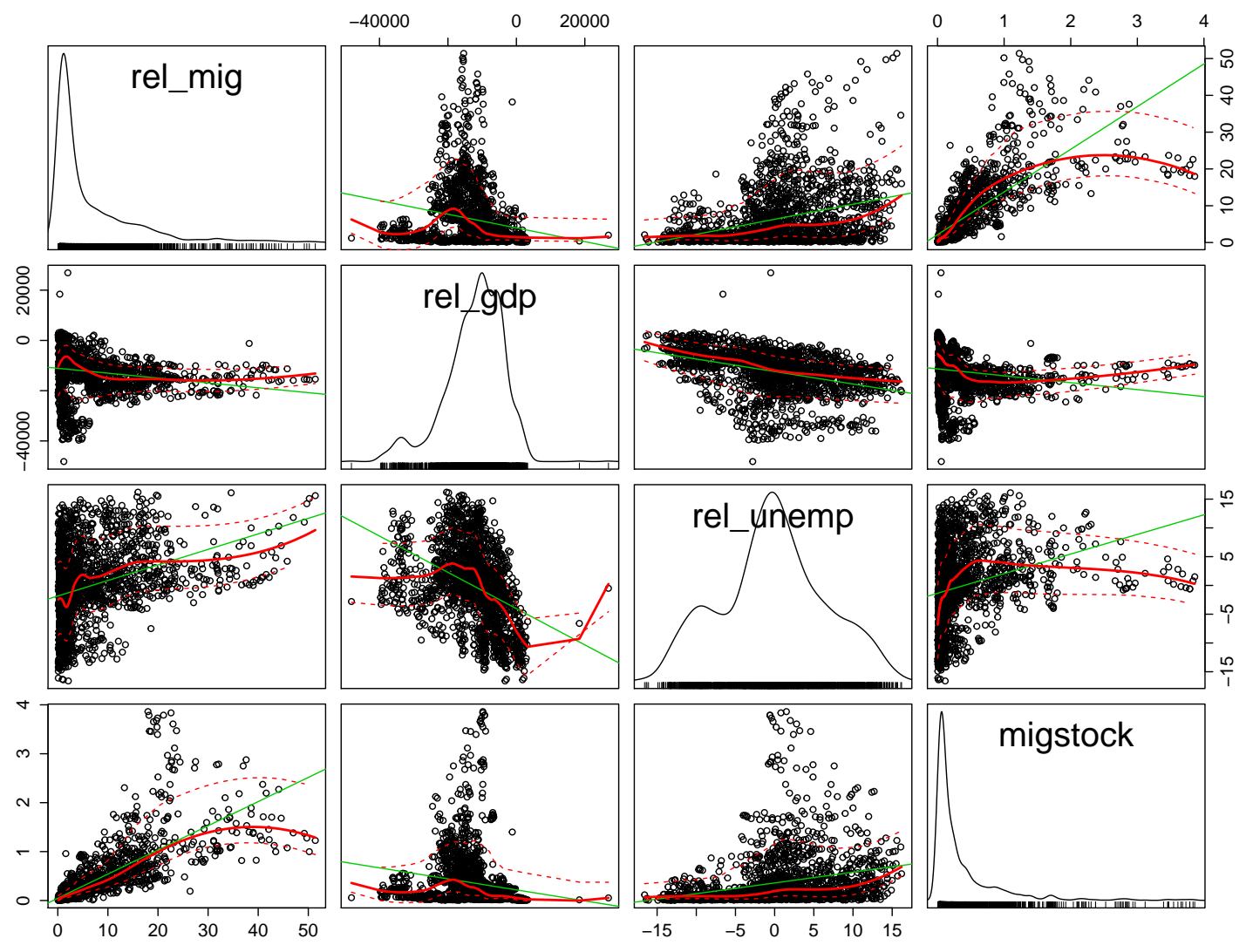

Figure 8: Pairwise plots 
Based on network theory we predicted that the migration flows to the different Bundesländer would vary more than predicted under economic variables. The differential rates of outmigration serve as an indication of different destination preferences. Referring back to figure 3 , it can be seen that there are fluctuations in relative migration flows to Bayern, Baden-Württemberg, Nordrhein-Westfalen, Berlin, Hessen, Niedersachsen and to some extent to Hessen. Interestingly, these Bundesländer have the highest reported levels of GDP per capita 95 The lowest levels of GDP per capita are reported in Thüringen, Sachsen-Anhalt and Mecklenburg-Vorpommern, which all have more homogenous and on average lower rates of migration than the higherincome Bundesländer. This is an interesting result, and could serve as an indication that if economic objectives are 'fulfilled', other non-economic arguments concerning the distribution of migrants are considered to be more important. These observed trends in migration flows are in line with what was argued in this paper, namely: both economic and networks variables are important in determining which destination region is favored.

However, to establish whether and how cause and effect are related requires a correlation analysis of the economic variables and migration flows, and migrant network variables and migration flows respectively. The correlation coefficient represents the respective sizes and directions of the linear relationships between these variables. Both correlations are expected to be positive. We expect to see that when economic differentials increase it is more likely that migration will increase. Similarly, as the size of migrant networks increases the flow of migrants is likely to be directed towards

\footnotetext{
${ }^{95}$ With the exception of Hamburg and Bremen, which have the highest GDP in the sample but do not display a lot of variation in relative migration flows.
} 
the regions where more nationals from the country of origin are located. As was described in the Empirical Analysis section, a Fixed Effects regression model will be employed to quantify the effect of different variables on migration flows.

Contrary to the expectation, there is a relatively small negative correlation $(\mathrm{r}=-$ 0.19) between relative GDP per capita and migration flows ${ }_{96}^{96}$ However, when looking at how relative GDP was calculated ${ }^{97}$ one would expect that as the negative sign increases, migration flows also increase. This is in line with the prediction that a larger potential gain in income will lead to an increase in migration flow, albeit a small increase. Migration flow and relative unemployment rates are characterized by a slightly larger and positive correlation coefficient $(\mathrm{r}=0.33)$, which is also in line with the expectations as previously described 98 Migrant stock and migration flows are highly correlated $(\mathrm{r}=0.76)$, and this also confirms the expectations ${ }^{99}$ However, it is not surprising that migrant stock and migrant flows are highly correlated. This might be partly due to the fact that they are inherently related. The more people move to a certain region, the higher the migrant stock in that region will be. However, since we are looking at the migrant stock at $t-1$ as a predictor for migrant flow at $t$, this finding does indicate there is a large positive relationship between the size of

\footnotetext{
${ }^{96}$ For the full table, please see the Appendices section.

${ }^{97}$ Relative GDP was calculated as: GDP in country of origin - GDP in destination region. Therefore, negative difference means GDP origin $<$ GDP destination, thus expect increase in migration, and vice versa.

${ }^{98}$ Relative unemployment rates were calculated as: unemployment rates country of origin - unemployment rates destination region. Thus, a negative difference in relative unemployment rates means that the unemployment rate at the origin $<$ unemployment rate at the destination, which has an expected negative effect on migration, and vice versa.

${ }^{99}$ Migrant stock was calculated as the proportion of the total population in the home country that is currently residing in the destination region. The larger this proportion, the larger the expected migrant flow.
} 
the migrant stock and the migrant flow in the following year.

Having established that 'cause' and 'effect' are related, we can proceed to the fixed effects regression. However, to verify that a fixed effects analysis is preferred over a random effects analysis in this case, we can conduct a Hausman test, which is used to decided between fixed and random effects by testing whether the unique errors are correlated with the regression coefficients 100 The Hausman test is based on running a fixed effects model and a random model on our data, saving the estimates and subsequently comparing these estimates 101 For this dataset the test result:102 indicate that the null hypothesis is rejected, and thus fixed effects is the preferred model for this analysis.

However, before we proceed to the regression analysis one of the assumptions of fixed effects regression needs to be discussed. As was discussed previously, fixed effects regression uses panel data to compare across entities. Figure 9 shows the heterogeneity in migration flows by destination ID. In this figure, ' $y$ ' is relative migration and 'y mean' is the mean migration, calculated over twelve years, to each destination.

Using fixed effects regression analysis three different models will be tested. The first model (1) regresses relative unemployment rates, relative wages and all other independent variables ${ }^{103}$ on relative migration flows. The second model (2) is testing

\footnotetext{
${ }^{100}$ The null hypothesis is that the preferred model is a random effects model. If we find a $\mathrm{p}<0.05$ for this test, the null hypothesis is rejected and the fixed effects model is the preferred model for the analysis.

${ }^{101}$ Please refer to the Appendices for the results of the Hausman test for fixed or random effects. ${ }^{102} \mathrm{p}>\operatorname{chi} 2=0.000$.

${ }^{103}$ Urban percentage, right-wing support, distance and migration policy.
} 


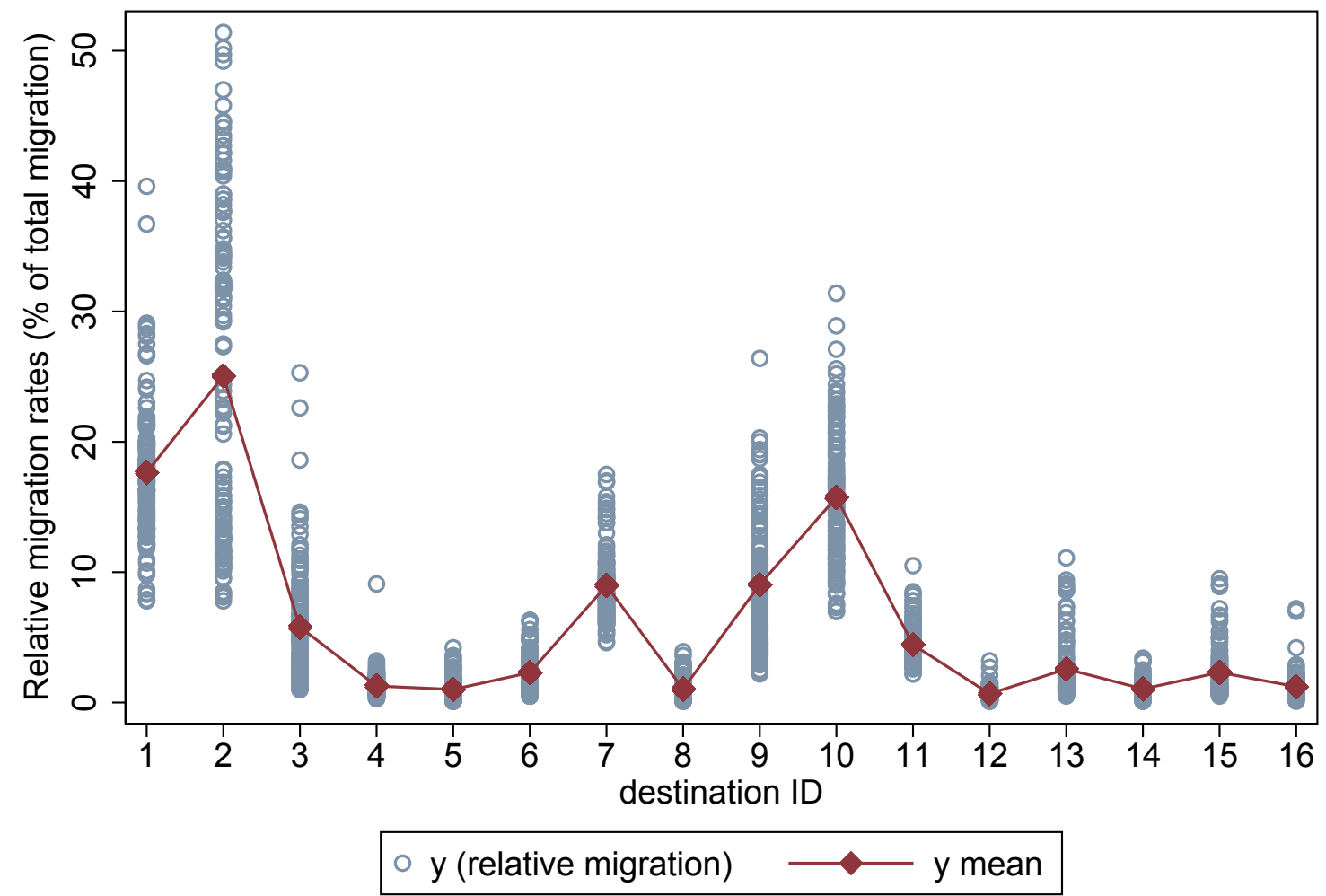

Figure 9: Heterogeneity in migration flows by destination ID. 
the effect of migrant stock and all other independent variables:404 migrant flows. Finally, the third model (3) regresses both the economic variables, migrant stock and all other independent variables on migrant flows. Table 2 displays the results of the three fixed effects regression analyses.

Before proceeding to the interpretation of the results, it is important to establish whether assumption of homoscedasticity ${ }^{105}$ has not been violated. Testing for heteroskedasticity in fixed effects regression models is done by using the Modified Wald test for group-wise heteroskedasticity ${ }^{106}$ The null hypothesis is that the variances are homoskedastic. The results of this test reports large p-values for all three models, indicating that the null hypothesis cannot be rejected. Thus, it is safe to assume there is no heteroskedasticity in all three models.

Both model (1) and model (3) report a small and negative significant coefficient for the effect of relative wages on migration flows. In the first model, if relative GDP increases by 1 unit ${ }^{107}$, migration flows decrease by -0.00018 . This coefficient would be more informative if we would multiply it by 1000, which would mean that an increase in relative GDP by 1.000 Euros ${ }^{108}$ is associated with a decrease in relative migration flows of 0.18 percent. In other words, if the difference in GDP between origin and destination decreases, the size of migrant flows also decreases. The same logic applies to the coefficient for relative GDP in the third model. This result confirms that indeed, the economic gains that can be made by migrating are a significant determinant of

\footnotetext{
${ }^{104}$ Excluding the economic variables from model (1).

${ }^{105}$ Constant variance.

${ }^{106}$ Please see the Appendices for the results of this test.

${ }^{107} 1$ unit $=1$ Euro.

${ }^{108} 1$ unit $=1000$ Euros.
} 
Dependent variable: relative migration flows

\begin{tabular}{|c|c|c|c|}
\hline & (1) & $(2)$ & $(3)$ \\
\hline & Economic Variables & Network Variables & Combination (1) and (2) \\
\hline \multirow[t]{2}{*}{ REL GDP } & -0.00018 & & -0.0001 \\
\hline & $(0.00004)^{* * *}$ & & $(0.00003)^{* * *}$ \\
\hline \multirow[t]{2}{*}{ REL UNEMP } & -0.0279 & & 0.0055 \\
\hline & $(0.025)$ & & $(0.0228)$ \\
\hline \multirow[t]{2}{*}{ MIGSTOCK } & & 4.466 & 4.576 \\
\hline & & $(0.223)^{* * *}$ & $(0.249)^{* * *}$ \\
\hline \multirow[t]{2}{*}{ URBAN } & 0.0243 & 0.0266 & 0.0271 \\
\hline & $(0.0161)$ & $(0.0147)^{*}$ & $(0.0149)^{*}$ \\
\hline \multirow[t]{2}{*}{ RWSUPPORT } & 0.023 & 0.1618 & 0.1078 \\
\hline & $(0.181)$ & $(0.155)$ & $(0.1666)$ \\
\hline \multirow[t]{2}{*}{ DIST } & -0.0028 & -0.0008 & -0.0014 \\
\hline & $(0.0004)^{* * *}$ & $(0.0002)^{* * *}$ & $(0.0004) * * *$ \\
\hline MIGPOL & omitted & omitted & omitted \\
\hline$N$ & 1920 & 2080 & 1920 \\
\hline$R^{2}$ within & 0.7476 & 0.7887 & 0.7860 \\
\hline$R^{2}$ between & 0.3310 & 0.0743 & 0.0522 \\
\hline$R^{2}$ overall & 0.7474 & 0.7848 & 0.7838 \\
\hline
\end{tabular}

Robust standard errors in parentheses. ${ }^{* * *}: \mathrm{p}<0.01,{ }^{* *}: \mathrm{p}<0.05,{ }^{*}: \mathrm{p}<0.1$

Table 2: Fixed effects regression results. 
migration flows. However, contrary to the expectations, unemployment differentials in both these models are non-significant determinants of migration. Migrant stock, which is reported in model (2) and model (3), is characterized by large coefficients (4.466 and 4.576 respectively) which are highly significant. This indicates, that as the size of the migrant stock increases by 1 percent of the total home country population, relative migration flows increase by roughly 4.5 percent. However, it should be noted that a one percent increase in migrant stock 109 corresponds to a very large increase in the absolute number of migrants.

Surprisingly, an increase in the support for the right wing extremist party NPD is associated with a slight, albeit insignificant, increase in migration flows. According to the result of this model, a one percent increase in votes for the NPD is associated with a 0.02 percent increase in migration flows. This result might be due to the fact that there were a limited number of observations available for this variable. The coefficients for the effect of distance between the country of origin and destination in all three model ${ }^{110}$ do confirm the expectation that an increase in the distance of 1 kilometer is associated with a small decrease in migration flows of roughly 0.001 percent. However, the fact that the coefficients are highly significant is does not confirm the prediction that because the distances between all Eastern European countries and the German destination regions are small one would expect that geographical distance would not be an important determinant of migrant flows. Unfortunately the variable Migrant flow was omitted from the analysis because of multicollinearity. Most likely this was due to the fact that there was insufficient available data

\footnotetext{
${ }^{109}$ As the proportion of the home country population.

$110-0.0028,-0.0008$ and -0.0014 respectively.
} 
on changes in migration policy, and migration policy was the same across all the different Bundesländer.

To assess the 'goodness of fit' of this model we need to refer to the $R^{2}$ values reported in Table 2. Fixed effects regression models report three different R-squared values, namely the overall, between and within measures of goodness of fit. The overall and between R-squares are calculated as the squared correlations. In order to make a statement about the percentage of the variance in the dependent variable that is explained by the model we need to look at the R-squared within value. The higher the value of the R-squared within coefficient, the better the model is fitted to the data. For all three models the reported values are between 0.75 and 0.79 , indicating that between 75 percent and 79 percent of the variation in the migration flows can be explained by the independent variables in these three models. To summarize, the models run here find support for the second hypothesi: ${ }^{111}$ and mixed support for the first 112 and the third hypothesis 113

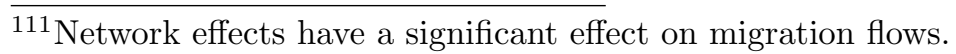

${ }^{112}$ Hypothesis 1 stated that both wages and unemployment differentials have a significant effect on migration flow, whereas this model only finds a significant effect for relative wages.

${ }^{113}$ Hypothesis 3 stated that network effects and economic variables, taken together, yield a more accurate prediction of migration flows. However, not all economic variables have a significant impact on migration flows.
} 


\section{Conclusions and Implications}

This thesis asked the following question: what factors influence the decision of migrants to migrate? It explored the relative importance of economic migration arguments versus migrant network parameters on a regional level in explaining and predicting migration flows. The analysis of these different variables found that both economic and network parameter ${ }^{114}$ play an important role in determining migration flows in the case of migration to Germany. It also found that there are indeed differences in the rates of outmigration from the different countries of origin to the different destination regions. Interestingly, those variations in outmigration were observed most clearly in destination regions characterized by favorable economic conditions. This paper has been examining mostly destination region characteristics. Further iterations of this project should explore the effects of country of origin characteristics, focusing on origin country migrant networks and institutions.

This study is a first attempt at understanding the various variables that influence migration decisions to different regions within a country. Future research could be directed towards adding more accurate predictor variables to the model, such as government bond yields as a measure of potential future economic security, the availability of unemployment benefits in the destination region and include a different measure of negative opinions about migrants. Also, a better measure of migration policy changes should be developed in order to test the effect of different exogenous policies on migrant flows.

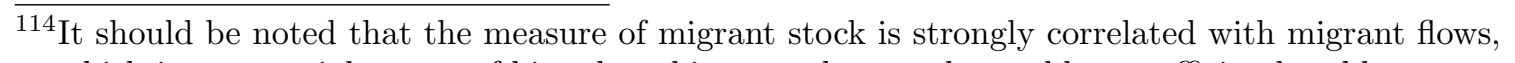
which is a potential source of bias that this paper has not been able to sufficiently address. 
Furthermore, there is detailed information available on the composition of the stock of migrants in the German Bundesländer in terms of the marital status and the gender of migrants. It would be interesting to explore the effects of migrant network composition on migration decisions. In addition, further exploration of better measures of migrant networks is necessary. In the case of Germany it could be useful to look at information form the German equivalent of the Chamber of commerce to obtain information on for instance the number of Polish shops that have been opened in a specific time period as an additional measure of the size and composition of a Polish migrant network. Lastly, future research should explore whether and how these Germany-specific results can be extrapolated to other regions and countries. 


\section{References}

[1] Berthold, N., Müller, A., Kosturkova, N. (2010) "Die Bundesländer im Standortwettbewerb 2009-2010: Einkommen, Beschäftigung, Sicherheit". Verlag Bertelsmann Stiftung.

[2] Bertoli, S., Brücker, H., Moraga, J.F.H. (2013) "The European Crisis and Migration to Germany: Expectations and the Diversion of Migration Flows". Forschungsinstitut zur Zukunft der Arbeit, Discussion Paper No. 7170.

[3] Boeri, T., Brücker, H. (2001) "Eastern Enlargement and EU Labor Markets: Perceptions, Challenges and Opportunities" Forschungsinstitut zur Zukunft der Arbeit, Discussion Paper 256.

[4] Brauw, de, A., Careletto, C. (2012) "Improving the Measurement and Policy Relevance of Migration information in Multi-Topic Household Surveys" Development Research Group, World Bank.

[5] Brenke, K. (2011) "Labor Mobility in Central and Eastern Europe: The Migration of Workers to Germany has been Limited in Scope". DIW Economic Bulletin.

[6] Brücker, H. (2007) "Labor Mobility After the European Union's Eastern Enlargement: Who Wins, Who Loses?" The German Marshall Fund of the United States.

[7] Dolfin, S., Genicot, G. (2010) "What Do Networks Do? The Role of Networks on Migration and "Coyote" Use". Review of Development Economics, Vol. 14, issue 2, pp. 343-359.

[8] EUROSTAT Regional GDP data <http://appsso.eurostat.ec.europa.eu/nui/show.do? dataset=nama_r_e2gdp\&lang $=e n>$

[9] EUROSTAT Statistics Explained <http://epp.eurostat.ec.europa.eu/statistics_explained/ index.php/Glossary:Purchasing_power_standard_(PPS) $>$

[10] EUROSTAT Unemployment Data <http://appsso.eurostat.ec.europa.eu/nui/show.do? dataset $=$ lfst_r_lfu3pers\&lang $=$ en $>$

[11] Fouarge, D., Ester, P. (2007) "Factors Determining International and Regional Migration in Europe" European Foundation for the Improvement of Living and Working Conditions, Dublin, Ireland. 
[12] GEObytes City Distance Tool <http://www.geobytes.com/citydistancetool.htm>

[13] German Bundestag Competentices of the German Federation and the Länder $<$ https://www.bundestag.de/htdocs_e/bundestag/function/legislation/ competencies/245700>

[14] German Federal Statistical Office: Bevölkerung und ErwerbstÄrtigkeit: Wanderungen (2010) <https://www.destatis.de/DE/ Publikationen/Thematisch/Bevoelkerung/Wanderungen/ Wanderungen2010120107004.pdf?__blob=publicationFile>

[15] German Federal Election Results <http://www.electionresources.org/de/bundestag.php?>

[16] Haas, H. (2010) "Migration Transistions: A Theoretical and Empirical Inquiry into the Developmental Drivers of International Migration" International Migration Institute, University of Oxford.

[17] Heiland, F. (2004) "Trends in East-West German Migration from 1989 to 2002". Demographic Research - Max Planck Institute, Vol. 11, article 7, pp. 173-194.

[18] Kahanec, M., Zaiceva, A., Zimmermann, K. (2009) "Lessons from Migration after EU Enlargement". Forschungsinstitut zur Zukunft der Arbeit, Discussion Paper No. 4230.

[19] Kurekova, L. (2011) "Theories of Migration: Conceptual Review and Empirical Testing in the Context of EU East-West Flows". Paper prepared for Interdisciplinary Conference on Migration, Economic Change and Social Challenges University College London.

[20] Leblang, D., Fitzgerald, J., Teets, J. (2007) "Defying the Law of Gravity: The Political Economy of International Migration". Department of Political Science, University of Colorado, Boulder.

[21] Massey, D.S., Arango, J., Hugo, G., Kouaouci, A., Pellegrino, A., Taylor, E.J. (1993) "Theories of International Migration: A Review and Appraisal". Population and Development Review, Vol. 19, No. 3, pp. 431-466.

[22] Migration Integration Policy Index Country Profile Germany $<$ http://www. mipex.eu/germany $>$

[23] Munshi, K. (2003) "Networks in the Modern Economy: Mexican Migrants in the U.S. Labor Market" The Quarterly Journal of Economics. 
[24] Noack, R., October 31, 2014. The Berlin Wall fell 25 Years Ago, but Germany is Still Divided, The Washington Post.

$<$ http://www.washingtonpost.com/blogs/worldviews/wp/2014/10/31/theberlin-wall-fell-25-years-ago-but-germany-is-still-divided/?tid=sm_fb $>$

[25] Princeton University Data and Statistical Services: Panel Data. $<$ http://dss.princeton.edu/online_help/stats_packages/stata/panel.htm>

[26] Rycx, F., Torejow, I., Valsamis, D. (2008) "Wage Differentials Across Sectors in Europe: An East West Comparison" European Trade Union Institute for Research, Education, Health and Safety.

[27] Schneider, J. (2012) "The Organization of Asylum and Migration Policies in Germany". Federal Office for Migration and Refugees, Working Paper 25.

[28] Spittel, M. (1998) "Testing Network Theory through an Analysis of Migration from Mexico to the United States". M.A. Thesis, University of WisconsinMadison.

[29] World Bank Data Urban Population as Percentage of Total Population $<$ http://data.worldbank.org/indicator/SP.URB.TOTL.IN.ZS>

[30] Zhao, Y. (2003) "The Role of Migrant Networks in Labor Migration: The Case of China" Contemporary Economic Policy, Vol. 21, No. 4, pp. 500-511. 


\section{Appendices}

\section{Relevant policy changes}

Most relevant policy changes for migration between 2000 and 2012:

2000: New citizenship law*

2004: Accession of the EU8 countries

2007: Accession of the EU2 countries

2009: Access to nationality security**

2011: End of 7 year restrictions on migration

*A new citizenship law came into force, the first such measure in nearly 90 years. For the very first time, children born to foreigners in Germany automatically receive German citizenship. ${ }^{115}$

**Amended nationality law places 5-year time limit on citizenship withdrawal for fraud 116

\footnotetext{
115 http://www.migrationpolicy.org/article/germany-immigration-transition

${ }^{116}$ http://www.mipex.eu/germany
} 


\section{Migration theories summary and critiques}

Table 3 summarizes the theories that were discussed and their main criticisms.

\begin{tabular}{llll}
\hline Theory & $\begin{array}{l}\text { Analysis } \\
\text { Level }\end{array}$ & $\begin{array}{l}\text { Important } \\
\text { Variables }\end{array}$ & Critiques \\
\hline $\begin{array}{l}\text { Neoclassical } \\
\text { Economic }\end{array}$ & Macro & Wage differentials & $\begin{array}{l}\text { Excludes politics and } \\
\text { policies, not able to } \\
\text { distinguish between } \\
\text { individuals }\end{array}$ \\
\hline $\begin{array}{l}\text { Neoclassical } \\
\text { Economic }\end{array}$ & Micro & $\begin{array}{l}\text { of wages and } \\
\text { probability of } \\
\text { employment }\end{array}$ & $\begin{array}{l}\text { Overestimates } \\
\text { incentives for } \\
\text { migration }\end{array}$ \\
\hline $\begin{array}{l}\text { New Economics } \\
\text { of Migration }\end{array}$ & Micro & $\begin{array}{l}\text { Wages and Income } \\
\text { distribution, market } \\
\text { imperfections }\end{array}$ & $\begin{array}{l}\text { Emphasizes the } \\
\text { sending country. } \\
\text { Mainly a critique of } \\
\text { Neoclassical theory }\end{array}$ \\
\hline $\begin{array}{l}\text { Dual Labor } \\
\text { Market }\end{array}$ & Macro & Labor Demand, FDI & $\begin{array}{l}\text { Cannot account for } \\
\text { fifferential migration } \\
\text { from similar } \\
\text { economies }\end{array}$ \\
\hline $\begin{array}{l}\text { World Systems } \\
\text { Network }\end{array}$ & Macro & $\begin{array}{l}\text { Structural changes as } \\
\text { result of capital flows }\end{array}$ & $\begin{array}{l}\text { Only works at } \\
\text { international level }\end{array}$ \\
\hline & Macro & Migrant Networks & $\begin{array}{l}\text { Networks can also } \\
\text { undermine migration, } \\
\text { not stimulate }\end{array}$ \\
\hline
\end{tabular}

Table 3: Theories of International Migration: Summary and Critiques. 


\section{Summary statistics}

Table 4 shows a summary of the relevant statistics used in this paper.

\begin{tabular}{lcllll}
\hline Variable & Observations & Mean & St. Dev. & Min & Max \\
\hline Rel. migration & 2080 & 6.258 & 8.202 & 0.1 & 51.4 \\
Rel. GDP & 1920 & -12302.92 & 8381.94 & -48200 & 26900 \\
Rel. unemployment & 2080 & 0.1927 & 6.592 & -16.6 & 16.2 \\
Migrant stock & 2080 & 0.3736 & 0.567 & 0.0029 & 3.924 \\
Urban percentage & 2080 & 23.622 & 33.215 & 3.258 & 98.599 \\
Right-wing support & 2080 & 1.268 & 1.3201 & 0 & 5 \\
Migration policy & 2080 & 0.3846 & 0.4867 & 0 & 1 \\
Distance & 2080 & 961.09 & 365.42 & 118 & 1623 \\
\hline
\end{tabular}

Table 4: Summary statistics.

\section{Correlation results}

Table 5 displays the results of the correlation analysis of migration flows with relative GDP, relative unemployment and migrant stock:

\begin{tabular}{lllll}
\hline & migration & GDP & unemp & migrant stock \\
\hline migration & 1.000 & & & \\
GDP & -.1901 & 1.0000 & & \\
unemployment & 0.3326 & -0.3960 & 1.0000 & \\
migrant stock & 0.7570 & -0.1759 & 0.2740 & 1.0000 \\
\hline
\end{tabular}

Table 5: Correlation results. 


\section{Results of the Hausman test}

Table 6] shows the results of the Hausman test.

\begin{tabular}{lllll}
\hline & Fixed & Random & Difference & S.E. \\
\hline Rel. GDP & -0.00012 & -0.00016 & 0.00004 & $8.34 \times 10^{-6}$ \\
Rel. unemp & 0.154687 & 0.0796 & 0.0750 & 0.01253 \\
Migstock & 10.3367 & 10.2939 & 0.07234 & 0.04115 \\
Urban perc. & -0.03834 & -0.04582 & 0.00745 & 0.0012 \\
RW support & -0.2369 & -0.2983 & 0.06138 & 0.1326 \\
Distance & -0.00143 & -0.00164 & 0.0002 &. \\
\hline \multicolumn{5}{c}{ Chi $^{2}(5)=35.22$, Prob $>\mathrm{chi}^{2}=0.0000$}
\end{tabular}

Table 6: Results Hausman test for fixed or random effects.

\section{Modified Wald heteroskedasticity tests}

Modified Wald test for group-wise heteroskedasticity in fixed effect regression model
Model (1)
$\operatorname{chi}^{2}(12)=2.18$
Prob $>$ chi $^{2}=0.9991$
Model (2)
$\operatorname{chi}^{2}(13)=8.44$
Prob $>$ chi $^{2}=0.8137$
Model (3)
$\operatorname{chi}^{2}(12)=5.45$
Prob $>\mathrm{chi}^{2}=0.9414$ 


\section{Acronyms}

Table 7 show the acronyms for Bundesländer as used in the coding of the data, as well as their respective capitals, and Table 8 shows the countries studied in this paper, with their capitals and acronyms.

\begin{tabular}{lll}
\hline Bundesland & Capital & Acronym \\
\hline Baden-Württemberg & Stuttgart & BW \\
Bayern & München & BA \\
Berlin & Berlin & BER \\
Brandenburg & Potsdam & BRA \\
Bremen & Bremen & BRE \\
Hamburg & Hamburg & HB \\
Hessen & Wiesbaden & HES \\
Mecklenburg-Vorpommern & Schwerin & MV \\
Niedersachsen & Hannover & NS \\
Nordrhein-Westfalen & Dusseldorf & NW \\
Rheinland-Pfalz & Mainz & RP \\
Saarland & Saarbrücken & SL \\
Sachsen & Dresden & SN \\
Sachsen-Anhalt & Magdeburg & SA \\
Schleswig-Holstein & Kiel & SH \\
Thüringen & Erfurt & TH \\
\hline
\end{tabular}

Table 7: German Bundesländer with their capitals and acronyms. 


\begin{tabular}{lll}
\hline Country & Capital & Acronym \\
\hline Germany & Berlin & GER \\
Czech Republic & Prague & CZE \\
Estonia & Talinn & EST \\
Hungary & Budapest & HUN \\
Latvia & Riga & LAT \\
Lithuania & Vilnius & LIT \\
Poland & Warsaw & POL \\
Slovakia & Bratislava & SLK \\
Slovenia & Ljubljana & SLV \\
Bulgaria & Sofia & BUL \\
Romania & Bucharest & ROM \\
\hline
\end{tabular}

Table 8: Countries, capitals and acronyms. 